\title{
El delincuente honrado de Jovellanos: estudio bibliográfico de ediciones tempranas y noticia de impresiones desconocidas (1773-1823)
}

\author{
Philip Deacon
}

Universidad de Sheffield, Reino Unido

En memoria de Nigel Glendinning

CES.XVIII, núm. 25 (2015), págs. 239-284. 


\section{RESUMEN}

Haciendo uso de los métodos de la bibliografía material este artículo intenta aclarar el número y la naturaleza de las ediciones tempranas de El delincuente honrado de Jovellanos. El trabajo estudia las veinte ediciones publicadas durante las cinco décadas posteriores a la composición original de la obra; los detalles de cada edición se proporcionan en un inventario que constituye la segunda parte del trabajo. El estudio analiza las ediciones, dividiéndolas en dos series, una basada en un texto no autorizado y otra que deriva de la versión aprobada por Jovellanos e impresa en 1787. El Inventario repasa cada edición, describiendo portada, colofón, formato, colación, paginación, texto empleado, versiones digitales disponibles, y apunta las signaturas de ejemplares en bibliotecas internacionales de referencia. El trabajo descubre la existencia de ediciones no conocidas hasta ahora y descarta las impresiones mencionadas en estudios anteriores de las que ninguna copia sobrevive.

Palabras clave

Gaspar de Jovellanos, El delincuente honrado, ediciones, impresores, bibliografía material, siglo XVIII, ediciones fantasma.

\section{Abstract}

Using the methods of analytical bibliography the article attempts to clarify the number and nature of the early editions of El delincuente honrado by Jovellanos. The article comprises a study of twenty editions published during the five decades after the work was written; details of each edition are given in the Inventory which constitutes the second part of the article. The study analyses the printings and describes their division into two series, one based on an unauthorized text and the other deriving from the version approved by the author and printed in 1787. The Inventory describes each edition in terms of title-page, colophon, format, collation, pagination, text used, listings in research bibliographies, digital versions available, and locations of copies in the world's major research libraries. The article brings to light previously unidentified editions of the work and rejects printings mentioned in earlier studies of which no copy survives.

\section{KeY Words}

Gaspar de Jovellanos, El delincuente honrado, editions, printers, critical bibliography, eighteenth century, phantom editions.

Recibido: 2 de septiembre de 2015. Aceptado: 30 de septiembre de 2015. 
Desde la publicación en 1984 de la edición crítica de El delincuente honrado a cargo de José Miguel Caso González, el texto dramático más destacado de Jovellanos ha provocado un renovado interés por sus ediciones primitivas así como por la evidencia que estas ofrecen del éxito de la obra entre el público lector a partir de su composición en $1773^{1}$. Siguiendo los pasos de Piero Menarini, que en 1974 había incluido unas importantes páginas sobre las ediciones del drama en un estudio centrado en su significado ideológico², Caso González realizó una lista provisional de las impresiones, dividiéndolas en dos tradiciones textuales, una respaldada por el autor y plasmada en el texto definitivo publicado por la viuda de Ibarra en 1787 (versión B), y otra, basada posiblemente en un manuscrito empleado para una representación temprana y editada varias veces sin el permiso de Jovellanos en fechas desconocidas (versión A), cuya primera edición por lo menos antecede a la autorizada por el autor ${ }^{3}$.

Dos años después de la edición de Caso González, Francisco Aguilar Piñal publicó el cuarto tomo de su gran Bibliografía de autores españoles del siglo XVIII, que proporciona información concreta sobre múltiples ediciones de El delincuente honrado, incluyendo, donde existían, detalles de fechas de impresión, nombres de impresores, lugares de imprenta, paginación, pertenencia a series numeradas de comedias y signaturas de bibliotecas internacionales en las que se custodiaban los ejemplares sobrevivientes ${ }^{4}$. Más recientemente, en 2008, en vísperas del bicentenario de la muerte de Jovellanos, Menarini volvió a la historia textual de la obra en una puesta al día de su estudio de tres décadas antes ${ }^{5}$; y, en el mismo año, la introducción a una nueva edición crítica del drama para una

\footnotetext{
1 Gaspar Melchor de Jovellanos, Obras completas I. Obras literarias, ed. José Miguel Caso González, Oviedo-Gijón, Centro de Estudios del Siglo XVIII-Ilustre Ayuntamiento de Gijón, 1984, págs. 467-565.

2 Piero Menarini, «Una commedia “politica” dell’'Illuminismo: El delincuente honrado di Jovellanos», en Finalità ideologiche e problematica letteraria in Salazar, Iriarte, Jovellanos, Pisa, Goliardica, 1974, págs. 93-168.

3 José Miguel Caso González, «Manuscritos y ediciones», en Jovellanos, Obras completas I, págs. 469-477.

4 Francisco Aguilar Piñal, Bibliografía de autores españoles del siglo XVIII, Madrid, Consejo Superior de Investigaciones Científicas, 1986, IV, págs. 682-736.

5 Piero Menarini, «La fortuna de El delincuente honrado de Jovellanos (ediciones, adaptaciones, traducciones», en Gaspar Melchor de Jovellanos, Il Torquato o sia L'onorato delinquente (El delincuente honrado), edición y estudio preliminar de Piero Menarini, Bolonia, Il Capitello del Sole (Iberica, Testi e Studi Ispanici 13. Sezione Settecento), 2008, págs. 5-25.
} 
serie de textos clásicos españoles por Russell P. Sebold, dio lugar a un repaso de las múltiples impresiones del Delincuente que sirvió para hacer hincapié en el éxito que la obra había tenido entre los lectores en las décadas posteriores a su composición ${ }^{6}$. Y, para concluir con los antecedentes del presente trabajo, en 2011 Noelia García Díaz recogió y contrastó los datos de las investigaciones publicadas hasta la fecha sobre el número e identidad de las ediciones de $E l$ delincuente honrado en una exposición sintética que abarcaba no solo las varias impresiones de las obras dramáticas de Jovellanos, sino también sus traducciones y los trabajos secundarios sobre ellas?

El objetivo del presente estudio es intentar establecer unos datos fiables sobre las impresiones tempranas de la obra empleando los métodos de la bibliografía material; su extensión cronológica incluye las cinco primeras décadas de vida del texto, y de esta manera pretende aportar evidencia de su fortuna entre el público hasta la tercera década del siglo XIX ${ }^{8}$. Como anticipo, diré que según la información que he podido reunir, hasta 1823 se publicaron veinte ediciones del drama, en Barcelona, Burdeos, Madrid, Valencia y otros lugares no identificados, más de la mitad de las cuales, once, emplearon el texto primitivo (versión A), mientras nueve se sirvieron de la versión fijada por el autor en 1787 (versión B). Al repasar la evidencia de la popularidad inicial de la que gozó el drama entre sus lectores, conviene tener en cuenta que ese éxito lo consiguió Jovellanos sin que su nombre apareciera en ninguna de las dieciocho ediciones publicadas en España hasta $1823^{9}$. La fama coetánea del drama efectivamente lo coloca en segundo lugar, detrás de $E l$ sí de las niñas, como el texto dramático impreso más popular de la época ${ }^{10}$. No obstante, con el objetivo de trazar su trayectoria editorial será necesario identificar de manera clara las distintas ediciones del texto, haciendo constar detalles de su impresión, formato y características tipográficas, además de precisar dónde se localizan los ejemplares que sobreviven en las bibliotecas internacionales de referencia. El estudio proporciona al final un inventario puntual de las ediciones, basado en la información recogida; pese

6 Russell P. Sebold, «Introducción» a Gaspar Melchor de Jovellanos, El delincuente honrado, Madrid, Cátedra (Letras Hispánicas, 612), 2008, págs. 87-88.

Noelia GARcía DíAz, «El teatro de Jovellanos. Ediciones, traducciones, bibliografía», Cuadernos de Estudios del Siglo XVIII, n. 20 (2010), págs. 177-195.

8 Aunque queda fuera del marco temporal del Inventario que acompaña este estudio, incluyo la edición de Pedro (Pierre) Beaume por cerrar el ciclo editorial de las impresiones bordelesas de la obra de Jovellanos en Francia en el primer tercio del siglo XIX.

9 Las excepciones son las editadas en Burdeos en 1818 y 1823 . Véanse las entradas 18 y 20 en el Inventario al final de este artículo.

10 Sobre el valor literario de la obra, véase el equilibrado y perspicaz estudio crítico de Elena de Lorenzo Álvarez, El delincuente honrado y el magistrado filósofo, lágrimas y virtud en escena, Gijón, Ayuntamiento de Gijón, 2012. 
a los riesgos de incurrir en inexactitudes en un trabajo de esta naturaleza, el presente artículo pretende avanzar en la información conocida sobre la historia editorial de este destacado drama sentimental.

\section{El estado de la cuestión}

Las palabras escritas por Jovellanos en 1787, escondiéndose tras el seudónimo de «Toribio Suarez de Langréo», aportan pruebas de la existencia de ediciones de El delincuente honrado anteriores a su impresión en aquel año por la imprenta de la viuda de Ibarra:

[...] la misma aceptación con que el público de España recibió el Delinqüente sugirió la idea de publicarle á uno de aquellos Impresores aventureros, que andan siempre á caza de obras expósitas librando sobre el crédito de ellas la ganancia que nunca podrian esperar del de sus prensas. Apareció en efecto el Delinqüente impreso en Barcelona: pero ¡valgame Dios, y quan desfigurado! Dígalo quien tuviere la paciencia de cotejar aquella edicion con la presente. ${ }^{11}$

Es importante notar que Jovellanos solo menciona una edición, sin dar el nombre del impresor, quizás por desconocerlo, y asegura que la impresión tuvo lugar en Barcelona. Una incógnita que se nos plantea, entonces, es la identidad de esa edición, ya que parece que once fueron impresas con un texto distinto del autorizado por su autor, de las que nueve dan Barcelona como lugar de impresión. Más de un siglo después, en 1901, el autodenominado «jovellanista» Julio Somoza se ocupó de manera formal de las ediciones tempranas, otorgando el título de primera edición a la impresa en Barcelona por Carlos Gibert y Tutó, sin revelar qué evidencia tenía para hacer tal afirmación y sin dar a entender que podría haber más de una impresión hecha por ese mismo impresor ${ }^{12}$. Su lista llegó a contabilizar siete ediciones en castellano entre 1773 y 1818, y a la vez descartó como «sospechosa» la afirmación de un historiador francés de que hubiera una edición temprana impresa en Madrid en $1780^{13}$.

11 [Gaspar Melchor de Jovellanos] Toribio Suarez de Langréo, El delinquente honrado, Madrid, Viuda de Ibarra, Hijos y Compañía, 1787, pág. V.

12 Julio Somoza de Montsoriú, Inventario de un jovellanista, con variada y copiosa noticia de impresos y manuscritos, publicaciones periódicas, traducciones, dedicatorias, epigrafía, grabado, escultura, etc., etc., Madrid, Establecimiento Tipográfico «Sucesores de Rivadeneyra», 1901, págs. 60-61.

13 Julio Somoza, Inventario de un jovellanista, pág. 53, declara «Si hubiéramos de dar algún crédito a un patrañero como Gaillard, el honor de la primera impresión de un escrito de Jove Llanos, con fecha conocida, correspondería a Madrid (El Delincuente Honrado, 1780); pero habremos de descartar esta referencia por sobrado 
Unos cinco lustros después, en la primera edición de su Manual del librero hispano-americano, el bibliógrafo catalán Antonio Palau y Dulcet citó también como primera edición del Delincuente una de Gibert y Tutó, que fecha, sin dar más explicaciones, «hacia $1782 »^{14}$. En total incluye en su bibliografía siete ediciones de la obra publicadas antes de 1828, dos de ellas en Burdeos. La segunda edición ampliada de su Manual, cuyo tomo correspondiente a Jovellanos vio la luz en 1954, no añade ningún dato de interés bibliográfico a la entrada sobre El delincuente honrado publicada en su edición anterior ${ }^{15}$.

El primer estudio razonado de las posibles ediciones primitivas del drama, por el profesor Piero Menarini, no se dio hasta 1974, limitando su cobertura a impresiones efectuadas hasta el año de la muerte de Jovino, en $1811^{16}$. Sus investigaciones dieron un total de ocho ediciones, tres de las cuales se atienen al texto establecido por el autor gijonés, mientras cinco siguen la versión no autorizada. Los comentarios que hace el estudioso italiano sobre cada edición son perspicaces e inician la tarea de desenredar el complejo entramado creado por unas impresiones en que faltan los datos básicos normalmente manejados en el mundo editorial español entre 1773 y 1823. El estudio, que tenía otras miras que identificar ediciones de la obra, resume el estado de la cuestión, después de aportar ocho páginas de análisis y comentarios:

La nostra bibliografia delle edizioni del Delincuente honrado, che videro la luce mentre l'autore era ancora in vita, termina senza la pretesa, ripetiamo, di essere completa o definitiva. Come si è visto, i problemi che essa suscita sono molti e troppo forse le ipotesi che bisogna avanzare per cercare di chiarirli ${ }^{17}$.

Afortunadamente, Menarini retoma el tema de manera más extensa en 2008, en un análisis al que se prestará atención más adelante.

Aunque el objetivo principal de José Caso en 1984 fue editar críticamente la poesía y las dos obras teatrales originales de Jovellanos, dedicó ocho páginas preliminares a enumerar y comentar los «Manuscritos y ediciones» de El delincuente, antes de ofrecer su texto crítico basado en la edición de la viuda de Iba-

sospechosa, para fijarnos en otra de mayor autenticidad, aunque de incierta fecha. Aludimos a la impresión hecha en Barcelona de El Delincuente, por Gibert y Tutó (impresor y librero), que por estar plagada de erratas, y hecha sin el consentimiento del autor, motivó la de Madrid de 1787». La mención de una posible edición de 1780 se encuentra en la entrada sobre Jovellanos en la Biographie universelle ou Dictionnaire historique, ed. François-Xavier FelLer et al., París, 1844, VII, pág. 47, además de en otras versiones de esta misma obra.

14 Antonio Palau y Dulcet, Manual del librero hispano-americano, Barcelona, 1926, IV, págs. 138-139.

15 Antonio Palau y Dulcet, Manual del librero hispano-americano, Oxford-Barcelona, 1954, VII, pág. 214.

16 Piero Menarini, «Una commedia “politica” dell’Illuminismo», págs. 109-117.

17 Piero Menarini, «Una commedia “politica” dell’Illuminismo», pág. 117. 
rra de 1787. A pesar de la preferencia dada al texto autorizado por Jovellanos, la edición de 1984 incluía al final las variantes principales de dos ediciones del texto primitivo impresas en Barcelona por Carlos Gibert y Tutó y Juan Francisco Piferrer, a las que Caso González añadía otras variantes significativas basadas en ediciones posteriores a la de 1787 que seguían el texto definitivo. Los párrafos preliminares dedicados a enumerar y comentar las ediciones tempranas del texto detallan tres — dos de Gibert y Tutó y una de Juan Francisco Piferrerque siguen la edición primitiva y no autorizada del texto, y nueve de la versión autorizada por Jovellanos publicadas hasta $1823^{18}$. Sin embargo, el eminente jovellanista admite no haber visto dos de estas ediciones (supuestamente impresas en Barcelona en 1806 y 1818), de las que solo tenía noticia a través del Inventario de Somoza de 1901.

Aunque el breve estudio de Caso González había precisado la localización de copias de algunas de las ediciones incluidas en su lista, el tomo pertinente de la Bibliografía de Aguilar Piñal publicado en 1986 avanzaba en la tarea de concretar en qué bibliotecas del mundo se encontraban ejemplares de las impresiones conocidas del drama de Jovellanos (con signaturas en muchos casos), y termina identificando un total de 12 ediciones distintas publicadas hasta el año de 1822, sin distinguir entre las que siguen la tradición textual A y las que pertenecen a la tradición B. Desde un principio se puede descartar la entrada 5.167 de la Bibliografía — menos completa que las demás en cuanto a detalles de impresor, fecha y lugar de publicación- porque el ejemplar citado (el único que figura) corresponde a una edición impresa en Barcelona por Manero a mediados del siglo XIX, y por tanto no tiene interés para nuestro estudio, centrado en impresiones hechas hasta 1823. En consecuencia, el número total de impresiones publicadas hasta aquel año según el profesor de investigación del CSIC puede cifrarse en 11, el mismo número que había calculado Caso González, aunque algunas ediciones de una lista no coinciden con las de la otra ${ }^{19}$. Es significativo que en ningún caso Aguilar Piñal registre más de cuatro ejemplares de la misma edición y que en cuatro de los casos consigne un solo ejemplar, aunque su repertorio incluye bibliotecas de España, Estados Unidos, Francia e Italia. Como se verá, los ejemplares de ciertas ediciones de la obra son muy raros.

En la «Bibliografía» que acompaña su texto de El delincuente honrado para la colección Letras Hispánicas de Ediciones Cátedra de 2008, Russell P.

18 Caso González, por tanto, fue el primero en revelar que había más de una edición impresa por Gibert. Véase Jovellanos, Obras completas I, pág. 471.

19 Aguilar Piñal solo incluye una edición de Gibert y Tutó y omite la supuesta de Barcelona de 1818 y la de Burdeos de 1823, aunque menciona las de la Viuda de Piferrer y de Roca (no presentes en la lista de Caso). Caso tampoco registra la edición de Valencia de 1815. 
Sebold, sin embargo, enumera 14 ediciones diferentes de la obra hasta 1823, aunque varias de las referencias carecen de nombre de impresor y parecen seguir las hechas por otros investigadores como Somoza y Caso (por ejemplo, las ediciones dudosas denominadas «Barcelona 1806» o «Barcelona 1818») ${ }^{20}$. El objetivo de su lista, que alcanza lo publicado hasta el año de 2006, parece el de recalcar la popularidad del texto de Jovellanos, indicando también el número de traducciones a otras lenguas europeas y ediciones impresas en castellano en países como Cuba, Estados Unidos y Francia.

Al publicar una edición bilingüe (español-italiano) del texto de Jovellanos en 2008, Piero Menarini volvió a la cuestión de las ediciones publicadas hasta la primera década del siglo XIX. En su nuevo estudio podía tener en cuenta los datos incluidos en la edición crítica de Caso González y lo aportado por la Bibliografía de Aguilar Piñal. Esta vez el estudioso italiano cautelosamente intenta poner fechas, aunque a veces muy aproximadas, a las ediciones incluidas. El número 3 de la lista es una entrada nueva, proponiendo la existencia de una primera edición temprana impresa por la viuda de Piferrer, y apoyando su propuesta en un ejemplar descubierto por Aguilar Piñal de la impresión de la misma impresora, que afirma que es «Corregida y enmendada en esta segunda impresión». Otra novedad son cuatro supuestas impresiones, fechables entre 1788 y 1792, que intentan explicar lo afirmado en la edición madrileña de 1793 de ser la sexta edición. El número 16 de la lista recoge, también de la Bibliografía de Aguilar Piñal, detalles de una impresión sin año hecha en Barcelona por Agustín Roca que el estudioso distingue de la supuesta edición de Barcelona, también inventariada por Aguilar, que parece ser una de las dos identificadas por Somoza un siglo antes. En todo momento el profesor Menarini explica sus razones para incluir nuevas ediciones y las justifica incorporando datos aportados por otros estudiosos o porque tiene en cuenta información sacada de los impresos mismos. Lo que sí habría sido deseable es que su estudio recogiera los datos precisos de dónde se encuentran los ejemplares concretos de cada edición que cita.

Hoy en día resulta cada vez más factible hacer un estudio bibliográfico detallado debido al fácil acceso a catálogos electrónicos online de las principales bibliotecas del mundo. Y también ahora suman más de veinte los catálogos impresos de colecciones importantes de comedias sueltas españolas en bibliotecas de investigación ${ }^{21}$. Algunos de estos repertorios incluso reproducen portadas de

20 Véase Russell P. SEBoLD, «Introducción», págs. 87-88.

21 Aparte de los catálogos citados en otras notas a lo largo del trabajo, he consultado los siguientes: Víctor ArizPe, The Spanish Drama Collection at the Ohio State University Library: A Descriptive Catalogue, Kassel, Reichenberger, 1990; Ídem, The «Teatro antiguo español» Collection at the Smith College Library. A 
ediciones en las que comprobar el diseño de la impresión de hace más de dos siglos y por tanto permiten distinguir a primera vista entre una edición y otra ${ }^{22}$. No obstante, ciertas complejidades de las ediciones de El delincuente honrado dificultan las búsquedas. El hecho de que dieciocho ediciones publicadas hasta 1823 carecen del nombre del autor obliga al investigador muchas veces a emplear el título de la obra como el factor principal al hacer uso del buscador electrónico, con la dificultad añadida de que algunos catálogos cambian la grafía «delinquente» de la mayoría de las impresiones tempranas a su forma más moderna de «delincuente». A pesar de estos estorbos, la identificación de las ediciones primitivas de El delincuente honrado se ve favorecida por el número de ellas que han sido digitalizadas y están disponibles en las páginas web de bibliotecas de investigación, además de por la política de la empresa Google de digitalizar los fondos antiguos de las grandes bibliotecas del mundo.

\section{Las bases de una investigación}

El presente estudio e inventario, por tanto, intentan aprovecharse de las novedades informáticas al alcance del investigador para reunir los detalles de todas las ediciones que ha sido posible identificar. Como punto de partida se han consultado cuatro grandes repertorios bibliográficos que pretenden ser

Descriptive Catalogue, Kassel, Reichenberger, 1996; B. B. Asнсом, A Descriptive Catalogue of the Spanish Comedias sueltas in the Wayne State University Library and the Private Library of Professor B. B. Ashcom, Detroit, Wayne State University Libraries, 1965; A. J. C. BAinTon, The Edward M. Wilson collection of Comedias sueltas in Cambridge University Library. A descriptive catalogue, Kassel, Reichenberger, 1987; Mildred V. BoYer, The Texas Collection of Comedias sueltas: A Descriptive Bibliography, Boston, G. K. Hall, 1978; Rafael GonZÁLEZ CAÑal y Ubaldo Cerezo Rubio, Catálogo de comedias sueltas del fondo Entrambasaguas, Kassel, Reichenberger, 1998; Karl C. Gregg, An Index to The Spanish Theatre Collection in the London Library, Charlottesville, Biblioteca Siglo de Oro, 1984; Ídem, An index to the teatro español collection in the Biblioteca de Palacio, Charlottesville, Biblioteca Siglo de Oro, 1987; William A. McKnight y Mabel Barrett Jones, A Catalogue of Comedias sueltas in the Library of the University of North Carolina, Chapel Hill, University of North Carolina Library, 1965; Juan Antonio MÉndez Aparicio, Catálogo de las obras de teatro impresas de los siglos XVI-XVIII de la Biblioteca Pública del Estado en Toledo, Madrid, Ministerio de Cultura, 1991; J. A. Molinaro, J. A. Parker y Evelyn RugG, A Bibliography of Comedias Sueltas in the University of Toronto Library, Toronto, University of Toronto Press, 1959; Orlando Moratinos Otero y Vicente Cueto Fernández, Bibliografía jovellanista, Gijón, Foro Jovellanos, 1998; Paul Patrick Rogers, The Spanish Drama Collection in the Oberlin College Library. A Descriptive Catalogue, Oberlin OH, Oberlin College, 1940; Edwin Sтавк, Die Sammling Spanischer comedias in der Universitätsbibliothek Freiburg, Kassel, Reichenberger, 2003; Szilvia E. SzmucK, A descriptive catalog of a collection of «Comedias sueltas» in the Hispanic Society of America. PhD Dissertation, City University of New York, Ann Arbor, University Microfilms International, 1985.

22 Un catálogo modélico a este respecto es el compilado por Germán Vega García-Luengos, Rosa Fernández Lera y Andrés del Rey Sayagués, Ediciones de teatro español en la Biblioteca de Menéndez Pelayo (hasta 1833), Kassel, Edition Reichenberger, 2001. Sus cuatro volúmenes son igualmente accesibles en una versión online a través de la Biblioteca Virtual Cervantes. 
completos dentro de los límites impuestos por sus principios fundacionales: el Catálogo Colectivo del Patrimonio Bibliográfico Español, el Catàleg Col-lectiu del Patrimoni Bibliogràfic de Catalunya, el Manual del librero hispanoamericano de Antonio Palau y Dulcet, y la Bibliografía de autores españoles del siglo XVIII de Francisco Aguilar Piñal. Igualmente, fueron consultados unos veinte catálogos dedicados a proporcionar datos analíticos de repertorios de comedias sueltas en diversas bibliotecas del mundo en las que se encuentran colecciones extensas de tales impresos. A continuación se han consultado los catálogos de tres grandes bibliotecas en España que contienen un número importante de ediciones de El delincuente honrado: la Biblioteca Nacional de España, la Biblioteca de Catalunya en Barcelona y la Biblioteca del Institut del Teatre de la Diputació de Barcelona. Luego se han realizado búsquedas en listados nacionales e internacionales online de los libros conservados en las grandes bibliotecas de investigación (BIMUS, COPAC, The European Library, Gallica, NUC, OCLC WorldCat, OPAC, REBIUN), seguidas por rastreos en los catálogos online de bibliotecas universitarias no incluidas o cuyos libros están descritos solo parcialmente en los catálogos ya mencionados. Y finalmente se ha buscado información a través del buscador internacional Google, que ha revelado ejemplares desconocidos de la obra de Jovellanos en bibliotecas insospechadas además de proporcionar a través de Google Libros copias digitalizadas de varios ejemplares de El delincuente honrado.

El primer paso en la identificación de las ediciones se ha efectuado como consecuencia de la transcripción detallada de la portada y el colofón (en caso de que lo haya) de una edición. Otros datos básicos son los detalles de los pliegos, con la serie alfabética o numérica de sus signaturas y la numeración de las páginas. En el caso de ediciones impresas por la familia Piferrer consignan el número de serie de su colección de comedias sueltas en la primera línea de lo impreso (en este caso el número 1); las ediciones salidas de las prensas de Carlos Gibert y Tutó emplean el número 67 para el mismo fin en la primera línea impresa de la primera página de texto. Si estos primeros indicios no revelan las diferencias entre ediciones la única prueba definitiva es el examen visual del impreso, que resulta imprescindible para detectar pequeñas diferencias en el diseño de las páginas y espaciado de las palabras y letras, especialmente cuando el impresor intenta imitar a plana y renglón una edición anterior, caso de las ediciones de Gibert y Tutó que emplean la «s» corta (Inv. 3 y 4$)^{23}$ y las tres de Juan Francisco Piferrer (Inv. 6, 7 y 8).

23 De aquí en adelante se remite a las distintas ediciones incluidas en el Inventario final por el uso de la abreviatura «Inv.» y el número correspondiente entre paréntesis después de mencionarlas. 
Resulta difícil de creer, pero hasta la edición crítica de El delincuente honrado por José Caso parece que nadie había señalado que varias impresiones tempranas de la obra ofrecían un texto básicamente distinto al autorizado por Jovellanos ${ }^{24}$. Dado que los primeros estudiosos de sus escritos habían establecido que la edición de 1787 recibió el beneplácito del autor, parecía obvio que para editarla solo había que prestar atención a esta versión del drama. Los párrafos preliminares al texto ofrecido por Caso y las variantes colocadas al final dejaron claro que la versión A de la obra era distinta y su transcripción por el erudito asturiano por fin permitía que el lector curioso las consultara para comprobar la naturaleza de esa otra versión que tiene interés para cualquier investigador comprometido con conocer la evolución textual de la obra de Jovellanos.

Lo que resulta igualmente difícil de creer es que nadie, excepto José Caso, haya examinado comparativamente las dos versiones para ver cómo la versión A da indicios de reflejar las primeras ideas del autor. La contundencia de la frase condenatoria del supuestamente «moderado» Jovellanos — «pero ¡valgame Dios, y quan desfigurado! Dígalo quien tuviere la paciencia de cotejar aquella edicion con la presente»- suena como una amenaza en la cabeza de quien piensa en la posibilidad de tomar en serio el texto A. José Caso, sin embargo, no temió afirmar que constituye «un texto distinto», añadiendo que «el que corría por los teatros (por algunos teatros, al menos) era una primera versión». Y concluyó afirmando que «debemos suponer que el texto editado en Barcelona representa la primera versión de Jovellanos $»^{25}$.

Las ediciones de la versión B, el texto fijado en 1787

Sabemos que incluso después del éxito inicial de su obra en los teatros de España, incluyendo uno de los teatros de los Reales Sitios, Jovellanos no quería que su nombre apareciera en la primera edición de 1787. Y eso fue después de que Juan Sempere y Guarinos, en su Ensayo de una biblioteca de los mejores escritores del reinado de Carlos III, revelara su autoría: «quiso probar sus fuerzas en los géneros épico, y dramático. A este último debemos referir el Delinquente Honrado, Comedia mal impresa en Barcelona, sin nota del año,

24 Me refiero a una versión distinta del texto, que tenga frases presentes en la versión alternativa o que elimine frases encontradas en la versión autorizada. La versión A de El delincuente honrado debe considerarse como un texto válido en sí, no meramente una versión con errores.

25 José Caso González, en Jovellanos, Obras completas I, pág. 474. 
y sin noticia de su autor» ${ }^{26}$. Después de dedicar tres páginas más a analizar la obra, concluye que «es sensible que una Comedia de estas circunstancias esté tan mal impresa, y muy de desear que su Autor la publique como salió de sus manos». El efecto de las palabras de Sempere, publicadas el año antes de la edición autorizada por Jovellanos, es querer condenar al olvido el texto de la versión original de la obra ${ }^{27}$. No obstante, como anticipé arriba, se imprimieron once ediciones de esta versión en las primeras décadas de vida de El delincuente, y por tanto la mayoría de los primeros lectores, en España por lo menos, habrían conocido la obra en una versión desautorizada por su autor. Parte de la culpa la tiene el mismo dramaturgo, pues consignar su nombre en las ediciones autorizadas en lugar de esconderse tras un seudónimo habría añadido peso a la importancia de leer el texto en la versión más correcta. En retrospectiva podemos señalar que el empleo del seudónimo en las portadas de impresiones posteriores a 1787 por lo menos ofrece un indicio de que el texto efectivamente es el autorizado. Las ediciones que siguieron a la de la viuda de Ibarra (Inv. 12), impresas principalmente en Madrid, pero también en Valencia, apuntan indirectamente a Jovellanos, subrayando la autenticidad del texto. Las impresas en Burdeos, tres en total hasta 1827 y todas póstumas, no dudan en atribuir El delincuente a su autor por su nombre, aunque en su impresión colocan la obra dramática después del diálogo en prosa de José de Cadalso las Noches lúgubres.

La impresión hecha en 1787 por la viuda de Joaquín Ibarra, Manuela Contera, es elegante, «linda» según Palau ${ }^{28}$. Tiene una «Advertencia del editor» antes del texto que explica los orígenes de la obra y de la edición, incluye una estampa que representa un momento clave en el argumento y como apéndice al final del texto reproduce la correspondencia entre Jovellanos y el traductor francés de la obra, Ange-François d'Eymard, abad de Valchrétien ${ }^{29}$. El breve intercambio de cartas revela aspectos del éxito teatral de la obra, especialmente en Cádiz, y añade comentarios importantes de Jovellanos sobre lo que pretendía en su texto desde una perspectiva jurídica, social y literaria.

26 Juan Sempere y Guarinos, Ensayo de una biblioteca española de los mejores escritores del reynado de Carlos III, Madrid, Imprenta Real, 1786, III, págs. 132-133.

27 El anuncio de la publicación del tomo tercero de la obra de Sempere se incluyó en la Gaceta de Madrid del 19 de diciembre de 1786, pág. 832.

28 Antonio Palau y Dulcet, Manual del librero, [1926], IV, pág. 138.

29 Sobre este traductor véase lo indicado en la «Liste des Messieurs de l'Académie des Belles-Lettres, Sciences et Arts de Marseille», en Recueil de l'Académie des Belles-Lettres, Sciences et Arts de Marseille, Pour l'Année 1774, Marsella, Imprimerie d'Antoine Favet, 1774, pág. 2. En la documentación impresa sobre el traductor consta que su nombre y apellido se escribían así. 
Esa primera impresión madrileña fue seguida por otras tres, una en 1793 y dos en 1803, todas las cuales emplean la versión B del texto ${ }^{30}$. No sobrevive evidencia de si estas ediciones se hicieron con la anuencia del autor. La de 1793 caía dentro de los diez años del privilegio que se supone concedido a la viuda de Ibarra en 1787; las de 1803 se imprimieron fuera del plazo oficialmente reglamentado y no hay constancia en la documentación conservada de que se renovaran los derechos del autor o impresor en los doce meses posteriores a la extinción del privilegio en $1797^{31}$. El hecho de que la impresa en 1793 (Inv. 13) afirma ser la sexta edición ha provocado comentarios explicativos de estudiosos posteriores de las ediciones como Menarini, que han sido recogidas por Noelia García Díaz $^{32}$. Si la de 1793, que no revela el nombre del impresor, pero sí la librería en Madrid donde se vendía (la de Quiroga), es la sexta, ¿cuáles son la segunda, tercera, cuarta y quinta? Resulta difícil creer que estas supuestas cuatro ediciones no hayan dejado rastro, y una explicación razonable es que el impresor de 1793 incluía en su total ediciones no autorizadas hechas en Barcelona. Solamente de la imprenta barcelonesa de Carlos Gibert y Tutó salieron cuatro ediciones del texto aunque no podemos establecer en qué años. Las dos posiblemente más antiguas (Inv. 1 y 2), por emplear la «s» larga, podrían ser dos de las aludidas por el impresor de 1793; la de la viuda de Piferrer (Inv. 5) podría ser otra, y una o las dos que carecen totalmente de lugar de impresión y de nombre de impresor (Inv. 10 y 11) podrían ser otras candidatas para resolver la cuestión de las cuatro ediciones que parecen faltar. Un dato no tenido en cuenta hasta ahora y que podría explicar la incógnita suscitada por el impresor de la edición de 1793 es que más de una impresión de una comedia suelta en Barcelona por Gibert indicaba que se vendía también en Madrid en la misma librería de Quiroga ${ }^{33}$, y una afirmación parecida está incluida en el colofón de dos ediciones de Juan Francisco Piferrer, dando a entender que varias ediciones barcelonesas por lo menos eran conocidas en Madrid y se vendían en las librerías de la capital de España.

Las dos nuevas ediciones de El delincuente fechadas en 1803 (Inv. 14 y 15) se imprimieron en Madrid, cuando el nombre de Jovellanos era más conocido

\footnotetext{
$30 \quad$ Para los detalles de estas ediciones, véase el Inventario al final de este artículo.

31 Véase Joaquín Álvarez Barrientos, Los hombres de letras en la España del siglo XVIII. Apóstoles y arribistas, Madrid, Castalia, 2006, págs. 244-253.

32 Piero Menarini, «La fortuna de El delincuente honrado...», pág. 7; Noelia García DíAz, «El teatro de Jovellanos...», págs. 180-181.

33 Un artículo de José Simón DíAz, «Don Ramón de la Cruz y las ediciones fraudulentas», Bibliografía Hispánica V (1946), págs. [715]-722, da cuenta de una querella contra Gibert por Ramón de la Cruz que le había acusado de imprimir sus textos en Barcelona sin su permiso. Reproduce una carta de Cruz del 9 de noviembre de 1786 dirigida a Quiroga como si fuera el intermediario madrileño en la venta de las impresiones hechas en Barcelona por Gibert. Véase pág. 718.
} 
en la esfera política después de la publicación del Informe sobre la ley agraria (1795) y su breve paso por el Ministerio de Gracia y Justicia (1797-1798) ${ }^{34}$. Pero el 13 de marzo de 1801 el ahora exministro había sido detenido por orden real y conducido a Mallorca sin conocer el motivo de su arresto. Confinado finalmente en el castillo de Bellver, fue tratado como un delincuente, sufriendo la incomunicación impuesta por Carlos IV sin saber de qué le acusaban, situación que se prolongó hasta marzo de $1808^{35}$. El gran intervalo entre 1803 y 1815, fecha esta de la primera impresión llevada a cabo en Valencia por Ildefonso Mompié (Inv. 16), puede explicarse por la situación turbulenta en España como consecuencia de la invasión francesa, el desorden del reinado de José Bonaparte y la vuelta a cierta normalidad después de la restauración de Fernando VII en $1814^{36}$. Sin embargo, desde finales de la misma década de 1810 varios impresores franceses empezaron a publicar textos españoles de cierto relieve, que encontraron una buena acogida entre españoles refugiados en Francia, en las librerías de España -frecuentemente las de Madrid_, y en los mercados de Hispanoamérica ${ }^{37}$. Las impresiones de El delincuente salidas de las prensas bordelesas de la familia Lawalle (Inv. 18 y 20) y la de Pierre (Pedro) Beaume (Inv. 21) se editaban junto a las Noches lúgubres de Cadalso y aparecen en ediciones en formatos muy manejables y con papel fuerte, aunque no son comparables con la elegancia de la edición de la viuda de Ibarra. En resumen, entre 1787 y 1827 se puede afirmar con seguridad que diez ediciones de El delincuente con el texto B fueron publicadas en Madrid, Valencia y Burdeos, todas con su fecha consignada, por lo que suelen resultar bastante fáciles de localizar e identificar.

Aunque el presente estudio no pretende analizar en detalle y de manera comparada las características del texto autorizado por Jovellanos, algunas

34 Sobre la carrera de Jovellanos véanse los estudios de Javier VARELA, Jovellanos, Madrid, Alianza, 1988, págs. 109-164, y José Miguel Caso GonzálEz, Vida y obra de Jovellanos, Oviedo, Caja de Asturias-El Comercio, 1993, págs. 411-439, 446-490.

35 Véanse las representaciones hechas por Jovellanos al Rey en Gaspar Melchor de JovelLanos, Obras completas, 11. Escritos políticos. Apéndices a la Memoria en defensa de la Junta Central. Núm. III. Libertad del autor, ed. Ignacio Fernández Sarasola, Oviedo-Gijón, Instituto Feijoo de Estudios del Siglo XVIII-Ayuntamiento de Gijón-KRK Ediciones, 2006, págs. 603-608.

36 The National Union Catalog. Pre-1956 Imprints, Londres, Mansell, 1967, vol. 285, pág. 608, entrada 0181375, menciona, sin embargo, una edición publicada en Madrid en 1814, de la que hasta la fecha no he podido localizar un ejemplar. Una consulta realizada por mí a la New York Public Library recibió la amable respuesta de uno de sus bibliotecarios de que hoy en día tal ejemplar no consta en la Biblioteca, afirmación que parece confirmada por su ausencia en el Catalogue de las comedias sueltas de dicha institución: Hannah E. Bergman y Szilvia E. Szmuk, A Catalogue of Comedias sueltas in the New York Public Library, Londres, Grant and Cutler, 1980-1981.

37 Véase el estudio y catálogo de Aline VAuchelle-HaQuet, Les ouvrages en langue espagnole publiés en France entre 1814 et 1833, Aix-en-Provence, Université de Provence, 1985. Se encuentran datos sobre las dos ediciones de la familia Lawalle en las págs. 107 y 136. 
observaciones pertinentes pueden hacerse. Una comparación somera de las dos series de ediciones revela unas diferencias globales y otras que suponen cambios léxicos o una reformulación de conceptos. Hay además frases en las dos versiones que no aparecen en la otra; es decir, Jovellanos llevó a cabo supresiones de ideas enteras al mismo tiempo que creaba otras nuevas entre el texto primitivo empleado en las ediciones anónimas o barcelonesas y el texto limado y cuidado de Madrid de 1787. Una diferencia que afecta a todo el texto es el empleo del pronombre en tercera persona en la versión A, escrito como «V.», «Vm.» o «Vmd.», en contraste con la forma «vosotros» usada en la serie B, partiendo de la edición de 1787. Otra diferencia, y más importante, entre las versiones A y B es la casi ausencia en la versión A de acotaciones que indican los movimientos y actitudes de los personajes. Por medio de esas acotaciones el lector sigue el vaivén de los sentimientos representados, indicaciones que contribuyen a comunicar de manera pormenorizada la perturbación interior representada por los personajes de un drama sentimental. Otro factor diferenciador que contribuye a la transmisión de las emociones inherentes en el argumento es el empleo de puntos suspensivos. Tales puntos son frecuentes en la versión $\mathrm{B}$, mientras su uso está muy reducido en las impresiones de la versión A.

Es posible suponer que al revisar su texto Jovellanos quería subrayar el juego de los sentimientos y emociones en la obra y por tanto abundan las acotaciones y puntos suspensivos que indican claramente a los actores cómo tienen que actuar, o, para el lector de las ediciones que emplean el texto B, sugerir la psicología y motivación de los personajes en los momentos en los que más interesa saber cómo piensan y lo que sienten. En estos dos aspectos la diferencia entre las dos versiones del texto es enorme y es importante subrayar que solo el lector de la versión B es capaz de entender plenamente qué significa el concepto de drama sentimental según lo interpretaba Jovellanos ${ }^{38}$. El lector de la versión A tendría que imaginar las emociones de un personaje por lo que dice, sin el comentario del autor que explica cómo se comporta y el grado de perturbación que debe mostrar. Otra diferencia pequeña aunque significativa de la versión A es la ausencia de la cita de Beccaria que viene al final de la versión autorizada de 1787, cita que podría incluso haber encabezado la edición como un epígrafe orientador para el lector. Las ediciones de la versión A también proclaman en la portada que los hechos representados en la obra se basan en un «caso sucedido

38 Para un planteamiento erudito y cabal de la poética del drama sentimental en España véase el estudio de María Jesús García Garrosa, «La comedia sentimental y la tragedia urbana», en El teatro en la España del siglo XVIII. Homenaje a Josep Maria Sala Valldaura, ed. Judith Farré, Nathalie Bittoun-Debruyne y Roberto Fernández, Lleida, Universitat de Lleida, 2012, págs. 141-158. 
en la ciudad de Segovia en el año de 1738», aunque está claro que el año debe ser $1758^{39}$.

Si, por otro lado, buscamos la explicación de las descripciones despectivas de la versión B, hechas tanto por Sempere como por Jovellanos, la encontramos en ciertos errores garrafales que una lectura atenta de los textos impresos habría revelado. En la escena 5 del Acto I, Torcuato está debatiendo el proceso legislativo con su suegro Simón. Al hablar de cómo la «estimación de los demás» puede aplicarse a «un hombre ilustre» sin que él pueda eliminarla, Torcuato pregunta «¿La nota que le impuso la opinion pública, podrá borrarla una sentencia?» en la versión $B$; en varias de sus impresiones el texto A decía « ¿la nota que le impuso la opinion Apostólica podrá borrarla una sentencia?» ${ }^{40}$. En el parlamento siguiente Torcuato afirma: «La buena Legislacion debe atender á todo, sin perder de vista el bien universal. Si la idea que se tiene del honor no parece justa, al Legislador toca rectificarla». En varias ediciones de la versión A la palabra final se lee ratificarla, justo lo contrario de lo que Torcuato piensa. Los errores de este tipo son escasos pero nos ayudan a entender los comentarios del autor al verlos y explicar por qué sentía la necesidad de dar a luz una edición corregida y autorizada de su texto.

\section{Las ediciones de la versión A, desde una perspectiva editorial}

En su condición de impresos en venta en España probablemente desde la década de 1770 hasta bien entrado el siglo XIX, las ediciones de El delincuente honrado que emplean la versión A del texto se sitúan fuera de la legalidad requerida $^{41}$. Todas carecen de fecha, y dos incluso de lugar de impresión y nombre de impresor (Inv. 10 y 11). Pertenecen a la categoría conocida como «comedias sueltas» en los estudios sobre las ediciones del teatro de los siglos XVI y XVII. Son ediciones con el formato en cuarto, hechas con papel de calidad inferior que pronto delatan el paso del tiempo y contrastan con la buena calidad de papel normalmente empleado para ediciones finas en octavo desde mediados del siglo XVIII. Las comedias de la época de extensión media suelen ocupar tres o

39 La equivocación de año se deduce por la fecha de la Pragmática (1757) que se refiere a las penas a imponer a personas implicadas en un duelo. Véase José Miguel Caso GonZÁLEZ, «Introducción» en Gaspar Melchor de Jovellanos, Escritos literarios, Madrid, Espasa-Calpe, 1987, págs. 76-77.

40 El empleo de cursiva en esta cita y las siguientes es mío. No todas las ediciones del texto A contienen este y el siguiente error; por ejemplo, la edición de la viuda de Piferrer es correcta.

41 Libro VIII, título XVI, ley XXII, en Novísima recopilación de las leyes de España, Madrid, 1805, pág. 133. 
cuatro pliegos en las ediciones en cuarto. El tipo de imprenta usual en las sueltas es pequeño, lo que podría dificultar su lectura. En la mayoría de los casos de sueltas que contienen el texto de El delincuente honrado se puede apreciar menos cuidado en el traslado del texto manuscrito o impreso empleado como original de imprenta. La puntuación suele ser algo errática y no acorde con la norma en impresos de finales del siglo XVIII. En el caso de El delincuente, una edición emplea una coma cuando otra emplea un punto y coma, y abunda el uso de dos puntos donde sería más normal emplear solo una coma. Igualmente variado es el uso de los acentos: algunos impresores emplean acentos graves para preposiciones como «à», mientras otros en los mismos casos emplean el acento agudo «á». De la misma manera, se nota una falta de corrección durante el proceso de impresión, práctica que permite la inclusión de muchas palabras que no tienen sentido en el contexto en el que se emplean. Y cuando uno compara pormenorizadamente una edición de la versión A del texto con la autorizada impresa por la viuda de Ibarra destacan otros muchos casos de lecturas de la versión A que podrían estar equivocadas.

La incógnita que nos plantean las once ediciones de El delincuente que emplean la versión A es si alguna de ellas puede identificarse como la primera, y por tanto, quizás, la que fue copiada por las posteriores. Para las ediciones con nombre de impresor es posible aventurar unas posibles fechas de impresión porque sabemos más o menos los años en que trabajaban, a veces con datos precisos sobre fechas de su muerte. Para las dos ediciones sin datos de impresión (Inv. 10 y 11) las dificultades y dudas son mucho más serias. Afortunadamente, nueve de las ediciones que emplean la versión A de El delincuente sí recogen el nombre de impresor: corresponden a las impresas por Carlos Gibert y Tutó, la viuda de Piferrer, Juan Francisco Piferrer y Agustín Roca.

Como se ha indicado más arriba, en 1901 Somoza señaló una edición de Carlos Gibert y Tutó como la más antigua, y sería por tanto la edición de Barcelona que había condenado Jovellanos por tener un texto «desfigurado». Lo que no sabía Somoza, ni Palau, es que hay cuatro versiones, no una, de ediciones impresas con un colofón que atribuye la impresión a Gibert (Inv. 1, 2, 3 y 4), un dato desconocido hasta ahora. Y como era costumbre, las cuatro llevan en la primera línea impresa de la primera página el número 67, que corresponde a su posición en la serie de comedias editadas por ese impresor, serie que alcanza más de 130 obras $^{42}$. En 1984 José Caso declaró que existían dos ediciones de Gibert, una que escribe la letra «s» según la manera moderna, como se acaba

42 Baso esta afirmación en un repaso de las ediciones de Gibert incluidas en el Catálogo Colectivo del Patrimonio Bibliográfico Español, consultado el 6 de setiembre de 2014. 
de hacer, y otra que emplea la «s» larga, es decir « $»$, al estilo antiguo. Sin embargo, en realidad hay dos ediciones en cada estilo. Sería lógico suponer que las ediciones con « $\int$ » sean anteriores a las que escriben la letra según el estilo más moderno, aunque esto no es posible garantizarlo. Y si pensamos que Gibert omitió la fecha de impresión para ocultar que estaba imprimiendo una edición no autorizada, un examen de las ediciones de comedias sueltas salidas de sus prensas demuestra que casi nunca ponía fecha de impresión ${ }^{43}$. Un repaso de las impresiones hechas en su taller indica que trabajaba como impresor entre los años 1773 y $1795^{44}$. Por lo tanto, podía haber impreso la primera edición de $E l$ delincuente honrado, como sospechaba Somoza. Dicho esto, conviene tener en cuenta que parecen sobrevivir, en las grandes bibliotecas mundiales con fondos antiguos, solo once ejemplares de El delincuente impresos por Gibert, de los que siete emplean la «s» larga. Más sorprendente aún es que quedan solo cuatro ejemplares de las dos ediciones con la «s» moderna. Y aunque José Caso había identificado en 1984 la existencia de dos ediciones impresas por Gibert, el $\mathrm{Ca}$ tálogo Colectivo del Patrimonio Bibliográfico Español registra una sola edición, basándose, uno supone, en los datos aportados por las bibliotecas participantes; además, la descripción incluida en su ficha no distingue entre el uso de la «s» corta o larga ${ }^{45}$.

Eulalia Massià de Piferrer, a veces bajo el título de la viuda de Piferrer, regentó la imprenta de su difunto marido Tomás, que murió en 1775, desde aproximadamente 1776 hasta $1793^{46}$. Su edición de El delincuente honrado (Inv. 5) podría, por tanto, ser la denunciada por Jovellanos si efectivamente se imprimió antes de 1787. Sin embargo, esta parece menos probable que otras candidatas a la condena de Jovellanos por ser una impresión bastante cuidada: hay pocos errores de ortografía (por descuido o por ignorancia del componedor), y entre las ediciones de la versión A del texto que he podido comprobar es de las más correctas. Piero Menarini suponía que la mención de ser la segunda edición corregida daba a entender que la misma impresora había editado otra anterior ${ }^{47}$. Como no existe más evidencia de tal edición que la deducción basada en lo que

\footnotetext{
43 Ibídem.

44 Para más información sobre Gibert, véase Jaime MoLL, «Un memorial del impresor y librero barcelonés Carlos Gibert y Tutó», en Homenaje a Federico Navarro: Miscelánea de estudios dedicados a su memoria, Madrid, Asociación Nacional de Archiveros, Bibliotecarios y Arqueólogos, 1973, págs. 317-329.

45 Según una consulta realizada el 5 de noviembre de 2014. La ficha registra ejemplares en cuatro bibliotecas españolas.

46 Sobre la familia Piferrer véase el artículo de Francesc Xavier Burgos y Manuel Peña DíAz, «Imprenta y negocio del libro en la Barcelona del siglo XviII. La familia Piferrer», Manuscrits. Revista d'Historia Moderna, n. ${ }^{\circ}$ (1987), págs. 181-216.

47 Piero Menarini, «La fortuna de El delincuente honrado...», págs. 6-7.
} 
reza la segunda, prefiero eliminar una supuesta «primera edición» hecha por la viuda de Piferrer del Inventario de las ediciones de El delincuente. Y puesto a explicar lo de «segunda edición corregida» me inclino a pensar que Eulalia Piferrer conocía una edición que le parecía mal impresa, es decir, con errores obvios de ortografía, y por eso proclama la calidad de corregida de la edición salida de sus prensas. Es posible suponer que sería aceptable darse cuenta de los errores y mala impresión en general de otro impresor rival y querer ofrecer una versión más correcta sin referirse a una impresión anterior hecha en el mismo taller. Un dato curioso de la impresión hecha por ella es que El delincuente honrado ocupa la primera posición en la serie de comedias editada por su imprenta. Cuando su hijo Juan Francisco Piferrer se hizo cargo del negocio, a la muerte de su madre en 1793, las tres nuevas impresiones del drama de Jovellanos siguieron ocupando el mismo número en la serie, como se puede apreciar en la transcripción de su primera página incluida en el Inventario (Inv. 6 a 8).

Las fechas de la actividad comercial de las dos generaciones de la familia Piferrer se extienden, por la actividad de Juan Francisco, hasta la cuarta década del siglo XIX, y por esta razón es posible que las últimas ediciones del texto de Jovellanos que llevan el nombre de Juan Francisco Piferrer como impresor en el colofón sobrepasen los límites de este estudio ${ }^{48}$. Piero Menarini atinadamente señalaba que una de las ediciones de Juan Francisco (Inv. 8) le declara «Impresor de S. M.» y ese hecho indica una fecha más bien tardía con respecto a las otras dos que imprimión ${ }^{49}$. José Caso, sin duda, desconocía las fechas de actividad de Juan Francisco y calculaba que una edición suya (Inv. 7) podría corresponder a una fecha en el siglo XVIII, posiblemente a una anterior a 1787, y por eso consignó las variantes encontradas en el ejemplar de una edición perteneciente a la Real Academia Española. Sin embargo, Piero Menarini, al tener en cuenta la edición impresa por la madre, colocó las ediciones de Juan Francisco en una fecha posterior a 1793. Pero mientras que el investigador italiano pudo identificar dos ediciones como impresas por Juan Francisco, he podido localizar tres, de las que dos se diferencian por cambios mínimos en el diseño de la página o espaciado de las palabras, aunque fáciles de distinguir por la manera de imprimir el colofón. En cambio, he tenido que excluir de mi Inventario de ediciones atribuibles a Juan Francisco Piferrer otra incluida en el Catálogo Colectivo del Patrimonio Bibliográfico Español. Me refiero al re-

48 Las últimas impresiones suyas registradas en el Catálogo Colectivo del Patrimonio Bibliográfico Español (consulta hecha el 5 de noviembre de 2014) son del año 1846. Su incorporación a la imprenta heredada de su madre parece haber ocurrido en 1794 según la información recogida en Centenario de la librería Bastiños, 1852-1952, Barcelona, José Bosch, 1952, pág. 14.

49 Piero Menarini, «La fortuna de El delincuente honrado...», pág. 8. 
gistro CCPB000323456-8, correspondiente a una impresión cuyo colofón reza: «Barcelona: En la Oficina de Juan Francisco Piferrer.». Al examinar dos de los tres ejemplares que supuestamente lo transcriben con estas palabras (uno de la Biblioteca de Catalunya y otro de la Biblioteca de la Real Academia Española), se ve que en realidad tienen las palabras «Barcelona: Por Juan Francisco Piferrer,... », tal como indican sus catálogos online, y corresponden a otras ediciones del mismo impresor ${ }^{50}$.

La novena impresión barcelonesa sin año de esta lista (Inv. 9) corresponde a la realizada por Agustín Roca. Lo más sorprendente de esta edición es que emplea la versión A del texto pese a que, con casi total seguridad, se imprimió después de 1804, puesto que los datos de que disponemos colocan todos los impresos que salieron de las prensas de Agustín Roca entre 1804 y 181951. Así que, aunque se imprimió por lo menos 17 años después de la edición autorizada del drama de Jovellanos, el texto fue, desde luego, el empleado ya por otros impresores barceloneses. Otro dato curioso es que a pesar de sus orígenes en la ciudad condal, no se encuentran ejemplares hoy día en ninguna biblioteca espanola. Los únicos que he podido localizar han ido a parar a bibliotecas del Reino Unido (Cambridge) y Estados Unidos (New Haven, Nueva York y Princeton). De las listas de obras teatrales publicadas por Roca antes de su muerte un $40 \%$ aproximadamente se publicaron sin fecha, por lo que la ausencia del año de impresión de la edición de El delincuente honrado no es significativa. A la luz de lo que han afirmado estudiosos como Somoza y otros sobre ediciones barcelonesas de 1806 y 1818 cualquiera de esas dos fechas podría corresponder a la edición impresa por Roca ${ }^{52}$. Y, dado que ningún ejemplar con esas fechas aparece en ninguna de las bibliotecas que he rastreado, sospecho que la existencia del texto impreso por Roca explica los datos dudosos sobre dos ediciones aparentemente con fechas de impresión pero sin nombre de impresor.

Al final de la lista de impresiones de El delincuente que siguen el texto A están dos raras ediciones carentes totalmente de datos sobre lugar, fecha de impresión y nombre de impresor (Inv. 10 y 11). De cada una solo han sobrevivido dos ejemplares, uno en España y otro en Nueva York. Por varias razones cualquiera de las dos podría ser la edición de Barcelona condenada por Jovellanos, y si damos crédito a las palabras escritas por el autor, la edición que se encuentra en la Biblioteca de Menéndez Pelayo en Santander y en la New York

\footnotetext{
50 Me ha confirmado la bibliotecaria Concha Nasarre que el ejemplar de la Diputación de Zaragoza (Inv. 6) tampoco tiene las palabras «En la Oficina de Juan Francisco Piferrer» en el colofón.

51 Según el Catálogo Colectivo del Patrimonio Bibliográfico Español (consulta hecha el 31 de agosto de 2015).

52 Julio Somoza, Inventario de un jovellanista, pág. 60.
} 
Public Library (Inv. 10) es la peor impresa de las once ediciones desautorizadas debido al poco cuidado tenido en su realización. Cada una de estas dos podría corresponder a la edición incluida como primera en la lista de Menarini cuya localización, sin embargo, no indica. El ejemplar de Santander (no he podido ver el de Nueva York) incluso tiene una de las erratas más garrafales en el Acto $\mathrm{V}$, escena 6 de la obra, cuando después de escaparse Torcuato de la pena capital con el perdón real ya hecho efectivo, don Justo sugiere que todos los presentes den gracias «a la Providencia»; la edición anónima, por contraste, pretende que las gracias se dirijan «a la Provincia».

La otra edición carente de datos de impresión, con ejemplares custodiados en la Biblioteca de Catalunya y la New York University Library (Inv. 11), no tiene tan graves errores de impresión como la que se acaba de mencionar pero sí resulta penosa de leer por los descuidos tipográficos. La lista de Menarini no habla de dos ediciones sin datos, sino de una, y por tanto la existencia de dos impresiones carentes de datos y que no son idénticas es otra novedad de esta investigación que conviene hacer constar.

Una constante de la búsqueda e identificación de textos impresos de $E l$ delincuente que siguen la versión A es la falta de ejemplares que sobreviven. La desaparición de tantos impresos suele interpretarse como síntoma del éxito de una obra, explicándolo como resultado de la manipulación de los ejemplares por un número tan grande de lectores que llega a producir el desgaste físico del papel, de modo que acaban por ser inservibles y se tiran a la basura. Por otra parte, el hecho de que una edición sobreviva hoy en día en un solo ejemplar o en dos — caso de varias ediciones de El delincuente- permite creer que otras impresiones mencionadas por investigadores del pasado hayan sufrido semejante suerte. No obstante, a fin de cuentas solo se pueden sacar conclusiones firmes basadas en ediciones que han sobrevivido y el Inventario que aparece al final de este artículo tiene por necesidad que basarse en los ejemplares que existen en realidad a día de hoy. Por esta razón creo que, hasta que no se encuentre nada que lo contradiga, cuatro supuestas ediciones de El delincuente honrado — las de Madrid 1780, Barcelona 1806, Madrid 1814 y Barcelona 1818- deben considerarse ediciones fantasma ${ }^{53}$.

Al llegar a este punto, podemos volver a especular sobre cuál de las ediciones corresponde a la denunciada por Jovellanos. Las dos de Gibert con la «s» larga son una posibilidad (Inv. 1 y 2 ); puede que Jovellanos las considerara una

53 La edición de Madrid 1814 fue mencionada por John Dowling en «La sincronía de El delincuente honrado de Jovellanos y las Noches lúgubres de Cadalso», Nueva Revista de Filología Hispánica, 33 (1984), págs. 219-223, en la pág. 220, citando como fuente de su información The National Union Catalog Pre-1956 Imprints, pero no parece haberlo confirmado con una consulta directa. 
porque las diferencias son mínimas y solo se constata que se trata en realidad de dos ediciones si uno las tiene delante. Otras dos posibilidades son las que carecen totalmente de datos sobre lugar y fecha de impresión y de nombre de impresor (Inv. 10 y 11). Sin embargo, la identidad correcta de la edición que en opinión de Jovellanos desfiguraba su texto no tiene tanta importancia a la luz de lo que podemos afirmar ahora de las impresiones desautorizadas. La búsqueda de ediciones y ejemplares tempranos de El delincuente honrado ha permitido identificar cuatro ediciones nuevas (Inv. 1, 4, 6 y 11), y lo que esas ediciones desconocidas demuestran es el éxito del drama sentimental para sus lectores durante unas cinco décadas.

\section{Conclusiones}

La afirmación más importante que se puede hacer sobre la historia editorial de El delincuente honrado es que se publicaron como mínimo veinte ediciones diferentes en un periodo de cincuenta años. Y los ejemplares de todas estas ediciones pueden consultarse en alguna biblioteca del mundo. La cifra total es quizás conservadora, porque en el curso de la investigación se han eliminado ediciones de las que ha sido imposible hallar rastro, aunque algún investigador o historiador ha alegado o supuesto su existencia. De esas veinte ediciones, nueve (posiblemente once) se imprimieron en Barcelona, sin la autorización de Jovellanos. Sin embargo, cuatro ediciones incluidas en el Inventario son nuevas en la bibliografía del autor (Inv. 1, 4, 6 y 11). La actitud de Jovellanos, al no autorizar una impresión hasta 1787, cuando una o más ediciones se habían publicado sin nombre de autor, y su insistencia en esa fecha tardía en que la edición fue «publicada», no escrita, por Toribio Suárez de Langreo, no ayudó a controlar el número de ediciones que emplearían un texto desautorizado por él.

Si suponemos que todas las ediciones tenían tiradas más o menos iguales de, quizás, 1.000 o 1.500 ejemplares, es probable que la mayoría de los lectores primitivos no leyeran la versión autorizada, sino una en que las características destacadas del drama sentimental (la abundancia de acotaciones sobre los sentimientos y el uso constante de puntos suspensivos) se habían reducido al mínimo. Eso no significa que los lectores originales no pudieran captar el tono de la obra, pero la experiencia lectora habría sido muy distinta de la de la edición de la viuda de Ibarra y las sucesivas que empleaban el texto autorizado.

Desde el punto de vista de la historia de la imprenta, este estudio subraya la importancia y dinamismo de Barcelona como centro editor, especialmente de comedias sueltas al alcance económico del público lector. En la ciudad condal 
se imprimieron dos veces más ediciones de la obra de Jovellanos que en Madrid (nueve — como mínimo- contra cuatro). Y la existencia de otros mercados sin satisfacer explica la existencia de tres ediciones de El delincuente impresas entre 1818 y 1827 en Burdeos, varios de cuyos ejemplares seguramente habrían pasado los Pirineos.

Desde una perspectiva bibliográfica, el estudio ha subrayado la importancia de la consulta minuciosa de ejemplares de las ediciones como base de una investigación sobre el número de impresiones que podría haber. Y la importancia de ver los ejemplares originales o copias de ellos para comparar directamente la disposición del texto e incluso el espaciado de las letras en la página es a fin de cuentas la única manera de distinguir una edición de otra. Desafortunadamente, algunos catálogos de biblioteca no incluyen todos los datos necesarios para identificar infaliblemente las ediciones de libros antiguos. Ciertos catálogos copian los datos de otros catálogos ya existentes, y en consecuencia su descripción puede ocultar la existencia de una impresión rara o incluso única, o incluyen datos en las descripciones que en realidad no figuran en el impreso. Afortunadamente la proliferación de copias digitales disponibles online de algunas bibliotecas con fondos antiguos está transformando las posibilidades de identificar esas ediciones raras, y su renovada disponibilidad por esta vía permite la consulta cada vez mayor de tales tesoros bibliográficos.

\section{Inventario de ediciones de El delincuente honrado hasta 1827}

En cuanto ha sido posible he examinado personalmente un ejemplar de cada edición importante de El delincuente. Cuando un examen personal no ha sido factible he consultado una copia de uno o más ejemplares; por copia entiendo fotocopia, copia escaneada o copia en forma digital. En el caso de impresiones de especial relevancia he mandado descripciones detalladas o copias de la primera y última páginas de la edición a un bibliotecario de la institución donde se custodia el ejemplar en cuestión para que confirmara los datos que acreditan su identidad. Para algunos ejemplares incluidos en esta lista he consultado, en los casos en que existen, los catálogos impresos de las colecciones importantes de comedias sueltas, por ejemplo, el de las Comedias sueltas in Cambridge University Library: A descriptive catalogue, de A. J. C. Bainton ${ }^{54}$ o el ya mencionado de Ediciones de teatro español en la Biblioteca de Menéndez

54 A. J. C. Bainton, Comedias sueltas in Cambridge University Library: a descriptive catalogue, Cambridge, The University Library, 1977. 
Pelayo (hasta 1833), compilado por Germán Vega García-Luengos, Rosa Fernández Lera y Andrés del Rey Sayagués. Estos dos repertorios han sido elaborados por profesores y bibliotecarios expertos, capaces de proporcionar los datos concretos exigidos por las normas de la bibliografía material para identificar los ejemplares de las ediciones incluidas. Y, finalmente, he recurrido a los catálogos online de múltiples bibliotecas que en muchos casos proporcionan datos suficientes para poder identificar los libros de manera bastante fiable. En el Inventario que sigue coloco en primer lugar las impresiones sin fecha, todas las cuales corresponden al texto primitivo (la versión A); parece probable también que todas fueran impresas en Barcelona aunque dos de ellas (Inv. 10 y 11) dejan de consignar el lugar de impresión.

De acuerdo con las normas empleadas en la bibliografía material para identificar las ediciones consigno en el Inventario a continuación el formato y colación de cada impresión encontrada. Como se ha señalado más arriba las ediciones no autorizadas (Inv. 1-11) se imprimieron con el formato en cuarto, es decir plegando dos veces las hojas proporcionadas por la fábrica de papel, con pliegos de ocho páginas de $20-21 \mathrm{~cm}$. de alto y $15 \mathrm{~cm}$. de ancho ${ }^{55}$. Con una sola excepción (Inv. 10), los impresores lograron incluir el texto completo de la obra en tres pliegos, normalmente identificados por letras (A-C $\mathrm{C}^{4}$ ), en un caso (Inv. 8) sustituidas por números $\left(1-3^{4}\right)^{56}$. La primera edición autorizada por Jovellanos (Inv. 12) estaba impresa con formato en octavo, plegando la hoja de papel tres veces, de lo que resultaban páginas más pequeñas (aprox. $15 \mathrm{~cm}$. por $10 \mathrm{~cm}$.). Las dos ediciones bordelesas salidas de la imprenta de Lawalle joven (Inv. 18 y 20) se imprimieron en forma aún más compacta, en dieciochoavo, con cuadernillos alternos de 12 y 6 hojas. Este formato pequeño estaba de moda en Europa a principios del siglo XIX, y permitía que el libro se llevara fácilmente en un bolso o bolsillo ${ }^{57}$.

Por último, quiero expresar mi agradecimiento a los bibliotecarios siguientes por su ayuda material y asesoramiento profesional: Iris Donovan (Berkeley, California CA), Giacomo Nerozzi (Bolonia), Mgr. Jitka Machova (Brno, República Checa), James Capobianco (Houghton Library, Cambridge MA), Liam Sims (Cambridge University Library, Reino Unido), Colin Higgins (St Catherine's

55 Sobre el análisis físico de los libros en la época de la impresión manual, véase Philip GASKELL, Nueva introducción a la bibliografía material, Gijón, Trea, 1999, especialmente págs. 65-66 y 97-128.

56 La falta de una letra o un número en el impreso está indicada por el empleo de corchetes cuadrados. El número volado registra las hojas correspondientes a cada pliego. Sobre la colación en la bibliografía analítica, véase Alberto Montaner Frutos, Prontuario de bibliografía. Pautas para la realización de descripciones, citas y repertorios, Gijón, Trea, 1999, págs. 138-141.

${ }_{57}$ Véase Gaskell, Nueva introducción a la bibliografía material, págs. 124 y 128. 
College, Cambridge, Reino Unido), Julia Gardner (Chicago IL), María Rosario Pizarro Quintanar (Ciudad Real), M. Knoll-Henschel (Freiburg), Almudena Martínez y P. Juan Bautista Olarte (Logroño y San Millán de la Cogolla), Guy Penman (The London Library), Jill Rosenshield (Madison WI), Ana Alberola, María Pilar Martínez Olmo y Alfredo Valverde (CSIC, Madrid), Paz García Ordóñez (Real Academia Española, Madrid), Paul Friedman (New York Public Library), Marvin J. Taylor (New York University Library), Lindsey Felice (Oberlin $\mathrm{OH}$ ), Judit Hidalgo Santamarta (Seminario Metropolitano de Oviedo), Lucy Evans (Oxford), Margarita Becedas González (Salamanca), Juan Antonio Ponce Prieto (Biblioteca Pública de Constantina, Sevilla), Eduardo Peñalver (Universidad de Sevilla), David Fernández, Liz Ridolfo y Miguel A. Torrens (Toronto), John Frederick (Victoria, Canadá), Karl-Heinz Bauer (Viena) y Concha Nasarre (Zaragoza). Sin su colaboración, además de la de varias bibliotecarias de la Biblioteca de Catalunya y de la Biblioteca Nacional de España, este trabajo no podría haberse llevado a cabo.

De forma particular quiero dar las gracias por sus consejos y ayuda en diferentes formas a Begoña Álvarez Ramos (Institut del Teatre, Barcelona), Gabriel Sánchez Espinosa (Queen's University, Belfast), Piero Menarini (Universidad de Bolonia), Noelia García Díaz y Elena de Lorenzo Álvarez (Universidad de Oviedo), Bonifacio Bartolomé (Archivo de la Catedral de Segovia), Luis Cardeña Gálvez (Biblioteca de Castilla-La Mancha, Toledo, España), María Jesús García Garrosa y Germán Vega García-Luengos (Universidad de Valladolid).

\section{Abreviaturas empleadas}

B: Datos confirmados por un bibliotecario de la institución donde se encuentra el ejemplar.

C: Ejemplar visto en una copia (completa o parcial) fotocopiada, escaneada o digitalizada.

CI: Datos confirmados por el catálogo impreso de comedias de la biblioteca en cuestión, dando en nota el nombre del autor del catálogo.

CO: Datos tomados del catálogo online de la biblioteca.

$\mathrm{E}$ : Ejemplar examinado en persona. 
1.

Portada: N. 67. 1 | TRAGI=COMEDIA. I EN PROSA. I EL DELINQUENTE I HONRADO. I Caso sucedido en la Ciudad de Segovia en el Año de 1738. I

Colofón: Barcelona: Por Carlos Gibert y Tutó, Impresor I y Librero. I

Otros datos importantes: Sin fecha, ni indicación de autor. Emplea la «s» larga: « $»$. Formato y colación: $4^{\circ}$. A-C .

Paginación: 1-24.

Fuente de la descripción: El ejemplar de la Biblioteca de Catalunya, 834-60 IX/11-8

Versión digitalizada: No consta.

Registro en el CCPBE: CCPB000673586-X. El registro confunde las cuatro ediciones de Gibert y Tutó, convirtiéndolas en una.

Registro en la Bibliografía de Aguilar Piñal: IV, 5164. La entrada confunde las cuatro ediciones de Gibert y Tutó, convirtiéndolas en una.

Íncipit: Torq. No hai remedio: es fuerza que yo tome algun partido;

Éxplicit: Jufto. Demos todos gracias à la inefable providencia, que nunca abandona à los virtuo 0 os, ni $\int e$ olvida de los inocentes oprimidos.

Versión del texto empleada: A.

Ejemplares localizados:

Barcelona, Biblioteca de Catalunya, 834-60 IX/11-8 (E).

Barcelona, Institut del Teatre, 58823 (E).

Chicago, Chicago University Library, PQ6532.J8D4 (B).

Toledo, Biblioteca de Castilla-La Mancha, 1-877 (4) (C).

2.

Portada: N. 67. 1 | TRAGI=COMEDIA | EN PROSA. I EL DELINQUENTE | HONRADO. I Caso sucedido en la Ciudad de Segovia en el Año de 1738. I

Colofón: Barcelona: Por Carlos Gibert y Tutó, Impresor I y Librero. I

Notas: En la portada de esta edición falta el punto después de «TRAGI=COMEDIA».

También en la segunda línea del listado de «Actores» la palabra «Padre» se imprime completa en esa línea, y no como «Pa- / dre», separada entre la primera y segunda líneas, como aparece en la edición anterior.

Otros datos importantes: Sin fecha, ni indicación de autor. Emplea la «s» larga: « $»$. Formato y colación: $4^{\circ}$. A-C 4 .

Paginación: 1-24.

Fuente de la descripción: El ejemplar de la Biblioteca Nacional de España, T-6975. 
Versión digitalizada: No consta.

Registro en el CCPBE: CCPB000673586-X. El registro confunde las cuatro ediciones de Gibert y Tutó, convirtiéndolas en una. Su lista registra cuatro ejemplares, de los que el ejemplar del Seminario de Barcelona corresponde a la edición descrita aquí.

Registro en la Bibliografía de Aguilar Piñal: IV, 5164. La entrada confunde las cuatro ediciones de Gibert y Tutó, convirtiéndolas en una.

Íncipit: Torq. No hai remedio: es fuerza que yo tome algun partido;

Éxplicit: Jufto. Demos todos gracias à la inefable providencia, que nunca abandona

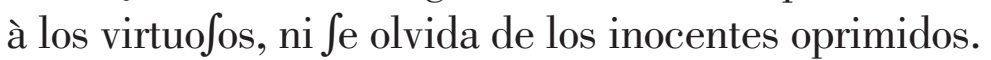

Versión del texto empleada: A.

Ejemplares localizados:

Barcelona, Biblioteca Pública Episcopal del Seminario de Barcelona, 860 Tra (E).

Barcelona, Institut del Teatre, 33342 (E).

Madrid, Biblioteca Nacional, T-6975 (E).

Notas: Caso González reproduce la portada de esta versión en su edición crítica de la obra de 1984 (pág. 472.); lo mismo hace Sebold en su edición de 2008 (pág. 105).

3.

Portada: N. 67. I I TRAGI=COMEDIA. I EN PROSA. I EL DELINQUENTE | HONRADO. I Caso sucedido en la Ciudad de Segovia en el año | de 1738. |

Colofón: Barcelona: Por Carlos Gibert y Tutó, Impresor I y Librero. I

Otros datos importantes: Sin fecha, ni indicación de autor. Emplea la «s» corta. Formato y colación: $4^{\circ}$. A- $\mathrm{C}^{4}$.

Paginación: 1-24.

Fuente de la descripción: El ejemplar de la Biblioteca Nacional de España, T-14845 (9).

Versión digitalizada: No consta.

Registro en el CCPBE: CCPB000673586-X. El registro confunde las cuatro ediciones de Gibert y Tutó, convirtiéndolas en una. Su lista registra cuatro ejemplares, ninguno de los cuales corresponde a la edición descrita aquí.

Registro en la Bibliografía de Aguilar Piñal: IV, 5164. Confunde las cuatro ediciones de Gibert y Tutó, convirtiéndolas en una.

Íncipit: Torq. No hai remedio: es fuerza que yo tome algun partido;

Éxplicit: Justo. Demos todos gracias à la inefable providencia, que nunca abandona à los virtuosos, ni se olvida de los inocentes oprimidos.

Versión del texto empleada: A. 
Ejemplares localizados:

Madrid, Biblioteca Histórica Municipal, Tea 1-103-12 (E).

Madrid, Biblioteca Nacional, T-14845 (9) (E).

Notas: El ejemplar de la Biblioteca Histórica Municipal de Madrid lleva la autorización para una representación de 1815.

4.

Portada: N. 67. I I TRAGI-COMEDIA. I EN PROSA. I EL DELINQUENTE I HONRADO. I Caso sucedido en la Ciudad de Segovia en el año I de 1738. I

Colofón: Barcelona: Por Carlos Gibert y Tutó, Impresor I y Librero. I

Notas: Esta edición se distingue fácilmente de la anterior por el uso de un solo guión en lugar de guiones dobles para escribir «TRAGI-COMEDIA».

Otros datos importantes: Sin fecha, ni indicación de autor. Emplea la «s» corta.

Formato y colación: $4^{\circ}$. A-C .

Paginación: 1-24.

Fuente de la descripción: El ejemplar del Archivo de la Catedral de Segovia, L-144-14-P.

Versión digitalizada: No consta.

Registro en el CCPBE: CCPB000673586-X. El registro confunde las cuatro ediciones de Gibert y Tutó, convirtiéndolas en una. Su lista incluye cuatro ejemplares, uno de los cuales, el de Segovia, corresponde a la edición descrita aquí.

Registro en la Bibliografía de Aguilar Piñal: IV, 5164. Confunde las cuatro ediciones de Gibert y Tutó, convirtiéndolas en una.

Íncipit: Torq. No hai remedio: es fuerza que yo tome algun partido las diligencias que se practican son mui vivas,

Éxplicit: Justo. Demos todos gracias à la inefable Providencia, que nunca abandona à los virtuosos, ni se olvida de los inocentes oprimidos.

Versión del texto empleada: A.

Ejemplares localizados:

Brno (República Checa), Moravská zemská knihovna, ST2-0001.632, 1/24 (C).

Segovia, Archivo Capitular de la Catedral, L-144-14-P (C).

Notas: Reproduzco la portada de esta edición, copiada del ejemplar de Segovia, como Fig. 1 al final de este Inventario.

5.

Portada: N. 1. 1 I TRAGI-COMEDIA. I EL DELINQUENTE I HONRADO. I Caso sucedido en la Ciudad de Segovia en el Año de 1738. I CORREGIDA Y ENMENDADA EN ESTA SEGUNDA IMPRESION. I 
Colofón: CON LICENCIA. I [Barra] | Barcelona: Por la Viuda Piferrer, vendese en su Li- I brería, administrada por Juan Sellent. I

Otros datos importantes: Carece de fecha y nombre de autor.

Formato y colación: $4^{\circ}$. A-C .

Paginación: 1-24.

Fuente de la descripción: La versión digital del ejemplar de la Biblioteca de la Universidad de Sevilla, A 250/237 (20).

Versión digitalizada: http://fondosdigitales.us.es/fondos/libros/5671.

Registro en el CCPBE: No consta.

Registro en la Bibliografía de Aguilar Piñal: IV, 5163.

Íncipit: Torq. No hay remedio: es fuerza que yo tome algun partido;

Éxplicit: Justo. Demos todos gracias á la inefable providencia, que nunca abandona á los virtuosos, ni se olvida de los inocentes oprimidos.

Versión del texto empleada: A.

Ejemplares localizados:

Sevilla, Biblioteca General de la Universidad, Fondo Antiguo A 250/237 (20) (C).

Notas: Un dato curioso sobre las relaciones entre las imprentas barcelonesas de Gibert y Piferrer es que Juan Sellent, el administrador de la imprenta de Piferrer cuando pertenecía a Eulalia Piferrer al igual que posteriormente a su hijo Juan Francisco, era yerno de Carlos Gibert y Tutó. Véase Simón DíAz, «Don Ramón de la Cruz ...», pág. 722.

6.

Portada: Núm. I. I TRAGI-COMEDIA: I EL DELINQUENTE I HONRADO. I Caso sucedido en la Ciudad de Segovia en el año de 1738. I

Colofón: Barcelona: Por Juan Francisco Piferrer, véndese en su Librería, administrada por I Juan Sellent; y en Madrid en la de Quiroga. I

Otros datos importantes: Carece de fecha y nombre de autor.

Formato y colación: $4^{\circ}$. A-C 4 .

Paginación: [1] 2-24.

Fuente de la descripción: El ejemplar de una biblioteca particular.

Versión digitalizada: Google Libros reproduce el ejemplar de la Biblioteca de Catalunya, 6-V-24/4.

Registro en el CCPBE: CCPB000481588-2. Registra solo el ejemplar de San Millán de la Cogolla.

Registro en la Bibliografía de Aguilar Piñal: IV, 5162. Confunde las tres ediciones de J. F. Piferrer, convirtiéndolas en una.

Íncipit: Torq. No hay remedio: es fuerza que yo tome algun partido; 
Éxplicit: Just. Demos todos gracias á la inefable providencia, que nunca abandona à los virtuosos, ni se olvida de los inocentes oprimidos.

Versión del texto empleada: A.

Ejemplares localizados:

Barcelona, Biblioteca de Catalunya, 6-V-24/4 (E).

Berkeley, University of California Library, PQ6218. C65 (B).

Freiburg, Staatsbibliothek, E 1032, nd-1 (CO y CI).

Madison, University of Wisconsin Library, PQ 6541 C6 1800 (B).

Oviedo, Biblioteca de Asturias «Ramón Pérez de Ayala», AST R C 152-2 (E).

San Millán de la Cogolla, Monasterio de San Millán de la Cogolla, B 200/5 (1) (B).

Toronto, University Library, buc pam 0654- FISHER (C).

Zaragoza, Biblioteca de la Diputación Provincial, F.A. 386 (4) (B).

Notas: Faltan las dos últimas páginas del ejemplar de la Biblioteca de Catalunya

(Sig. 6-V-24/4) y por tanto carece del colofón para poder identificar al impresor. La edición está atribuida equivocadamente a Gibert y Tutó en el Catálogo online de la Biblioteca, cuya entrada remite a una copia digital supuestamente de la edición de Gibert que resulta ser de esta de Piferrer.

El ejemplar perteneciente a la Biblioteca de la Diputación Provincial de Zaragoza es de esta edición; no constituye una versión distinta tal como da a entender el registro CCPB000323456-8 del Catálogo Colectivo del Patrimonio Bibliográfico Español.

Reproduzco la portada de esta edición como Fig. 2 al final de este Inventario.

7.

Portada: Núm. I. I I TRAGI-COMEDIA: I EL DELINQUENTE | HONRADO. I Caso sucedido en la Ciudad de Segovia en el año de 1738. I

Colofón: Barcelona: Por Juan Francisco Piferrer, véndese en su Librería, administrada I por Juan Sellent; y en Madrid en la de Quiroga. I

Notas: Esta edición se distingue fácilmente de la anterior por la posición del cambio de línea en el colofón, es decir antes, y no después, de la palabra «por».

Otros datos importantes: Carece de fecha y nombre de autor.

Formato y colación: $4^{\circ}$. A-C .

Paginación: 1-24.

Fuente de la descripción: El ejemplar de la Real Academia Española, 41-V-28 (2).

Versión digitalizada: Google Libros reproduce el ejemplar de la Biblioteca de Catalunya, Tus Res 164-8 ${ }^{\circ}$. Hay otra versión digitalizada disponible a través del ejemplar de Munich: Bayerische StaatsBibliothek digital, 4 P.o.hisp. 28 i-1/48\#Cah.9. 
Registro en el CCPBE: En realidad no consta. El registro CCPB000481588-2 del CCPBE confunde dos ediciones parecidas, esta y el número 6 arriba.

Registro en la Bibliografía de Aguilar Piñal: IV, 5162. Confunde las tres ediciones de J. F. Piferrer, convirtiéndolas en una.

Íncipit: Torq. No hay remedio: es fuerza que yo tome algun partido;

Éxplicit: Just. Demos todos gracias á la inefable providencia, que nunca abandona á los virtuosos, ni se olvida de los inocentes oprimidos.

Versión del texto empleada: A.

Ejemplares localizados:

Barcelona, Biblioteca de Catalunya, Tus Res 164-8 (E); 834.61 Com 7/9 8 (E).

Barcelona, Institut del Teatre, 44419 (E).

Berkeley, University of California Library, PQ6217.A2 C6442 v.3:8 (B).

Londres, The London Library, P956 (B).

Madrid, Real Academia Española, 41-V-28 (2) (E).

Munich, Bayerische StaatsBibliothek, 4 P.o.hisp. 28-i-1/48 (C).

Victoria (Canadá), University of Victoria Library, Special Collections, PQ6500 A1D4 1700z (B).

8.

Portada: Núm. 1. 1 I TRAGI-COMEDIA: | EL DELINCUENTE | HONRADO. | Caso sucedido en la ciudad de Segovia en el año de 1738. I

Colofón: Barcelona: Por D. Juan Francisco Piferrer, Impresor de S. M. I

Otros datos importantes: Carece de fecha y nombre de autor.

Formato y colación: $4^{\mathrm{o}}$. 1-3 .

Paginación: 1-24.

Fuente de la descripción: El ejemplar de una biblioteca particular.

Versión digitalizada: No consta.

Registro en el CCPBE: No consta.

Registro en la Bibliografía de Aguilar Piñal: IV, 5162. Confunde las tres ediciones de J. F. Piferrer, convirtiéndolas en una.

Íncipit: Torc. No hay remedio es fuerza que yo tome algun partido,

Éxplicit: Just. Demos todos gracias á la inefable providencia, que nunca abandona á los virtuosos, ni se olvida de los inocentes oprimidos.

Versión del texto empleada: A.

Ejemplares localizados:

Barcelona, Biblioteca de Catalunya, 16-III-16 (E); 83-8-C 93/20 (E).

Barcelona, Institut del Teatre, 44702 (E); 90587 (E).

Ciudad Real, Biblioteca de la Universidad de Castilla-La Mancha, E 9635 (I) (B).

Filadelfia, Pennsylvania University Library, SC75 A100 Pam v.1 (CO). 
Madrid, CCHS del CSIC. Biblioteca Tomás Navarro Tomás, Fondo antiguo RES/7078 (8) (B).

Nápoles, Biblioteca Nazionale di Napoli, L.P. Seconda Sala 08. 5. 10 (CO).

Oxford, Bodleian Library, (Vet) 38654 d.6 (18) (B).

Notas: La grafía «c» en el nombre de Torcuato parece evidenciar una impresión de esta edición posterior a las dos anteriores de este Inventario.

Reproduzco la portada de esta edición como Fig. 3 al final de este Inventario.

9.

Portada: Núm. 14. I TRAGI-COMEDIA: I EL DELINQUENTE I HONRADO. I Caso sucedido en la Ciudad de Segovia en el año de 1738. I

Colofón: BARCELONA: I POR AgUSTIN Roca. I Á Costa de los Libreros asociados. I Otros datos importantes: Carece de fecha y nombre de autor.

Formato y colación: $4^{\circ}$. A-C .

Paginación: 1-24.

Fuente de la descripción: Los ejemplares de la Cambridge University Library, Hisp.5.76.33 (5) y Hisp.5.76.26 (10).

Versión digitalizada: No consta.

Registro en el CCPBE: No consta, porque no parece haber ejemplares en bibliotecas públicas en España.

Registro en la Bibliografía de Aguilar Piñal: IV, 5166.

Íncipit: Torq. No hay remedio: es fuerza que yo tome algun partido;

Éxplicit: Just. Demos todos gracias á la inefable providencia, que nunca abandona á los virtuosos, ni se olvida de los inocentes oprimidos.

Versión del texto empleada: A.

Ejemplares localizados:

Cambridge (Reino Unido), University Library, Hisp.5.76.33 (5) (E); Hisp.5.76.26 (10) $(\mathrm{E})^{58}$.

New Haven, Yale University Library - Beinecke, He35 617 (CO).

Nueva York, New York Public Library, NAFH p.v. $576\left(\mathrm{CO}\right.$ y CI $\left.{ }^{59}\right)$.

Princeton, University Library, Special Collections Rare Books 31661.999 v.33 (CO).

10.

Portada: TRAGI-COMEDIA I EN PROSA. I EL DELINQUENTE I HONRADO. I Caso sucedido en la Ciudad de Segovia en el año I de 1738. I pág. 69.

58 La edición está descrita en A. J. C. BainTon, Comedias sueltas in Cambridge University Library,

59 La edición está descrita en el catálogo de Hannah E. Bergman y Szilvia E. Szmuk, A Catalogue of Comedias sueltas in the New York Public Library, pág. 93, entrada 340 
Otros datos importantes: Carece de información sobre nombre de autor, impresor, lugar y año de publicación.

Formato y colación: $4^{\circ}$. A- $\mathrm{C}^{4}, \mathrm{D}^{1}$.

Paginación: [1] 2-26.

Fuente de la descripción: Una copia digital del ejemplar de la Biblioteca de Menéndez Pelayo, 32.244.

Versión digitalizada: No consta.

Registro en el CCPBE: No consta.

Registro en la Bibliografía de Aguilar Piñal: No consta.

Íncipit: Torq. No hay remedio: es fuerza que yo tome algun partido:

Éxplicit: Just. Demos todos gracias á la inefable Providencia, que nunca abandona á los virtuosos, ni se olvida de los inocentes oprimidos.

Versión del texto empleada: A.

Ejemplares localizados:

Nueva York, New York Public Library, NPL p.v. $208\left(\mathrm{CI}^{60}\right)$.

Santander, Biblioteca de Menéndez Pelayo, 32.244 ( $\left.\mathrm{C}^{61}\right)$.

Notas: El catálogo impreso de comedias de la Wayne State University Library de Detroit por Howard A. Sullivan y Henry N. Bershas, The Wayne State University Collection of Comedias Sueltas. A Descriptive Bibliography (Detroit, Wayne State University Press, 1984), tenía una edición cuyas características coincidían con esta pero el ejemplar no figura hoy en día en el catálogo online de esta biblioteca.

11.

Portada: TRAGI-COMEDIA I EN PROSA. I EL DELINQUENTE I HONRADO. I Caso sucedido en la Ciudad de Segovia en el año I de 1738. |

Notas: Esta edición se diferencia fácilmente de la anterior por su número de páginas.

Otros datos importantes: Carece de información sobre nombre de autor, impresor, lugar y año de publicación.

Formato y colación: $4^{\mathrm{o}}$. A-C $\mathrm{C}^{4}$.

Paginación: [1] 2-24.

Fuente de la descripción: El ejemplar de la Biblioteca de Catalunya, Tor. 1060/7-8

60 Esta edición está descrita en el catálogo de Hannah E. Bergman y Szilvia E. Szmuk, A Catalogue of Comedias sueltas in the New York Public Library, pág. 93, entrada 339.

${ }_{61}$ El catálogo impreso y online de la Biblioteca de Menéndez Pelayo reproduce la portada de esta edición. Véase Germán Vega García-Luengos et al, Ediciones de teatro español en la Biblioteca de Menéndez Pelayo, IV, pág. 1728, además de incluir la descripción detallada en el vol. I, pág. 318, entrada 1160. 
Versión digitalizada: No consta.

Registro en el CCPBE: No consta.

Registro en la Bibliografía de Aguilar Piñal: No consta.

Íncipit: Torq. No hay remedio: es fuerza que yo tome algun partido:

Éxplicit: Just. Demos todos gracias á la inefable Providencia, que nunca abandona á los virtuosos, ni se olvida de los inocentes oprimidos.

Versión del texto empleada: A.

Ejemplares localizados:

Barcelona, Biblioteca de Catalunya, Tor 1060/7-8 (E).

Nueva York, New York University. Elmer Holmes Bobst Library, PQ 6523.F355 A5 1745 (B).

Notas: Es posible que esta descripción corresponda a la edición mencionada por Menarini, «La fortuna de El delincuente honrado», pág. 5, entrada 1.

12.

Portada: EL DELINQUENTE I HONRADO, I COMEDIA EN PROSA. I PUBLÍCALA I D. Toribio Suarez de Langréo [sic]. I [Adorno: Monograma de Ibarra] I MADRID MDCCLXXXVII. I Por la Viuda de Ibarra, Hijos y Compañía. I CON LICENCIA. I Formato y colación: $8^{\circ} . \mathrm{a}^{6}, a-g^{8}, h^{2}, i^{8}, k^{6}$.

Paginación: [2] [I] II-VIII, [2] [1] 2-143. Con estampa en la contraportada.

Fuente de la descripción: El ejemplar de la Biblioteca Nacional de España, T-11421.

Versiones digitalizadas: La Biblioteca Digital Hispánica reproduce completo el ejemplar de la Biblioteca Nacional, T-9735 (2). También hay una versión de Google Libros que termina en la pág. 116, donde concluye el texto de la obra.

Registro en el CCPBE: CCPB000715757-6. Registra un solo ejemplar, en el Seminario Metropolitano de Oviedo.

Registro en la Bibliografía de Aguilar Piñal: IV, 5161.

Íncipit: Torquato. No hay remedio: ya es preciso tomar algun partido.

Éxplicit: Just. [...] Vamos á tratar de vuestro destino, y demos gracias á la inefable Providencia que nunca abandona á los virtuosos, ni se olvida de los inocentes oprimidos.

Versión del texto empleada: B.

Ejemplares localizados:

Austin, University of Texas Library, Harry Ransom Center Book Collection, PQ 6532 J7 D34 1787 (CO).

Barcelona, Biblioteca de Catalunya, 83-8-10608 (E); 5/21225 (E).

Barcelona, Institut del Teatre, 51583 (E).

Bilbao, Biblioteca de la Universidad de Deusto, 099 BB"17" J 78 g (CO). 
Madrid, Biblioteca Nacional, T-11421 (E); T-9735 (2) (E); T-10532 (dañado en las págs. 75-78) (E).

Nueva York, New York Public Library, NPO (Trigueros, C.M. Sancho Ortiz de las Roelas 1800) (CO).

Oviedo, Seminario Metropolitano de Oviedo, Asturias-2188 (1) (B).

Oxford, Bodleian Library, $8^{\circ}$ M 24 (1) Art.BS (CO).

Parma, Biblioteca Palatina, PR0072 PARPA (CO).

Notas: Esta edición incluye al principio una «Advertencia del editor» sobre los orígenes de la obra y la correspondencia entre Jovellanos y su traductor francés después del texto.

13.

Portada: EL DELINQUENTE I HONRADO. I COMEDIA EN PROSA. I PUBLICALA I DON TORIBIO SUAREZ | DE LANGREDO [sic]. I FIELMENTE CORREGIDA, ADICCIONADA [sic] Y ENMENDADA | EN ESTA SEXTA IMPRESION. I [Adorno] I CON LICENCIA. I MADRID: AÑO DE 1793. I Se hallará en la Librería de Quiroga calle de la Concepcion. I

Formato y colación: $4^{\text {o }}$. [a] b-d ${ }^{4}$.

Paginación: [1-2] 3-32.

Fuente de la descripción: El ejemplar en la Biblioteca Nacional de España, T-14988 (8).

Versión digitalizada: No consta.

Registro en el CCPBE: CCPB000058073-2.

Registro en la Bibliografía de Aguilar Piñal: IV, 5165.

Íncipit: Torq. No hay remedio: ya es preciso tomar algun partido.

Éxplicit: Just. [...] Vamos á tratar de vuestro destino, y demos gracias á la inefable Providencia que nunca abandona á los virtuosos, ni se olvida de los inocentes oprimidos.

Versión del texto empleada: B.

Ejemplares localizados:

Barcelona, Institut del Teatre, 33309 (E); 33321 (E).

Berlín, Staatsbibliothek, 18 in: Xk 1427 (CO).

Cambridge (MA), Houghton Harvard Depository, Span 4391.20 (CO).

Cambridge (Reino Unido), St Catherine's College Library, Chaytor JS.5.3005 (CO).

Madrid, Biblioteca Nacional, T-14988 (8) (E).

Madrid, CSIC. Biblioteca Tomás Navarro Tomás, Fondo antiguo. Res 6893 (14) (CO).

Oxford, Taylor Institution Library, VET.SPAN.III.B.84 (1) (CO).

París, Bibliothèque Nationale, 8 YG PIECE 497 (CO). 
14.

Portada: EL DELINQUENTE I HONRADO. I COMEDIA EN PROSA. I PUBLICALA I DON TORIBIO SUAREZ I DE LANGREO. I FIELMENTE CORREGIDA, ADICIONADA Y EMENDADA I EN ESTA SEPTIMA IMPRESION. I [Adorno: Motivo floral.] I CON LICENCIA. I MADRID: AÑO DE 1803. I Se hallará en la Librería de Quiroga, Calle de Carretas. I

Colofón: Se hallará ésta y otras varias en la Librería de Quiroga calle I de Carretas, con un gran surtido de Comedias, Tragedias, Au- | tos Sacramentales, Trinólogos, Diálogos y Unipersonales, I como tambien de Saynetes y Entremeses.

Formato y colación: $4^{\mathrm{o}}$ : [A] B-D ${ }^{4}$.

Paginación: [1-2] 3-32.

Fuente de la descripción: El ejemplar de la British Library, 11726.c.5 (1).

Versión digitalizada: La Hathi Digital Trust Library reproduce el ejemplar de la Universidad de Minnesota, 863J829 OD.

Registro en el CCPBE: No consta.

Registro en la Bibliografía de Aguilar Piñal: No consta.

Íncipit: Torq. No hay remedio: ya es preciso tomar algun partido.

Éxplicit: Just. [...] Vamos á tratar de vuestro destino, y demos gracias á la inefable Providencia que nunca abandona á los virtuosos, ni se olvida de los inocentes oprimidos.

Versión del texto empleada: B.

Ejemplares localizados:

Almagro, Biblioteca Museo Nacional del Teatro, Bueno FA 10 COM (6) (CO).

Londres, British Library, 11726.c.5 (1) (E).

Londres, The London Library, P966-3 (B).

Minneapolis, University of Minnesota Library, 863J829 OD (CO).

Notas: Ubaldo Cerezo Rubio y Rafael González Cañal mencionan en la versión impresa del Catálogo de comedias sueltas del Museo Nacional del Teatro de Almagro (Madrid, Centro de Documentación Teatral, Instituto Nacional de las Artes Escénicas y la Música, Ministerio de Cultura - Universidad de Castilla-La Mancha, 1994, pág. 151) que existe un ejemplar de esta edición en la Biblioteca de la Universidad de North Carolina, pero resulta ser de la «octava edición».

15.

Portada: EL DELINQÜENTE I HONRADO, I COMEDIA EN PROSA, I EN CINCO ACTOS. I PUBLÍCALA I Don Toribio Suarez de Langréo [sic]. I OCTAVA EDICION. | CON LICENCIA: EN MADRID: I En la Imprenta de García y Compañía. I AÑO DE 1803. I Se hallará en la librería de Quiroga, calle I de las Carretas. I 
Formato y colación: $8^{\circ}$. A-I ${ }^{8}$.

Paginación: [1-3] 4-142 [143-144].

Fuente de la descripción: El ejemplar de la British Library, 11725.a.30.

Versión digitalizada: La Biblioteca Digital Hispánica reproduce el ejemplar de la Biblioteca Nacional de España, U-11038 (5). Google Libros reproduce el ejemplar de la Biblioteca de Catalunya, 082Var 13/9-12 $2^{\circ}$, del que faltan las págs. [1]-4.

Registro en el CCPBE: CCPB000202328-8.

Registro en la Bibliografía de Aguilar Piñal: IV, 5168.

Íncipit: Torquato. No hay remedio: ya es preciso tomar algun partido.

Éxplicit: Sim [sic]. [...] Vamos á tratar de vuestro destino, y demos gracias á la inefable Providencia, que nunca abandona á los virtuosos, ni se olvida de los inocentes oprimidos.

Versión del texto empleada: B.

Ejemplares localizados:

Barcelona, Biblioteca de Catalunya, 082Var 13/9-12 (CO).

Barcelona, Institut del Teatre, 31601 (E); 45988 (E); 62255 (E).

Berlín, Staatsbibliothek, Xk 8706 (CO); Xk 2100-670-1 (CO).

Boston, Boston Public Library, Ticknor Collection D 170a.15 (CI $\left.{ }^{62}\right)$.

Cambridge (Reino Unido), University Library, Pam.8.80.26 (E).

Chapel Hill, University of North Carolina Library, Rare Book Collection PQ 6217.T443v.14, no. 1 (CO).

Ciudad Real, Biblioteca de la Universidad de Castilla-La Mancha, Campus de Ciudad Real, E 582 (II) (CO).

Evanston (IL), Northwestern University Library, 862.4 M831s.3 (CO).

Londres, British Library, 11725.a.30 (E).

Madrid, Biblioteca Complutense, Biblioteca Histórica-Fondo antiguo (F), FA 16594 (CO).

Madrid, Biblioteca Histórica Municipal, Tea 1-103-12, b (E).

Madrid, Biblioteca Nacional, T-15298 (13) (E); U-11038 (5) (E).

Madrid, CSIC M-Resid, S6994 (B).

Santiago de Compostela, Biblioteca Universitaria, Biblioteca Xeral, RSE.OPUSC 155 (CO).

Sevilla, Biblioteca Colombina, 37-1-42 (1) (CO).

Sevilla, Biblioteca Pública Municipal, 0300(03) (B).

${ }^{62}$ Para el catálogo impreso de la biblioteca de Ticknor véase James Lyman Whitner, Catalogue of the Spanish Library and of the Portuguese Books bequeathed by George Ticknor to the Boston Public Library, Boston, 1879. 
Valencia, Biblioteca Universitaria, BH T/1043 (1) (CO).

Zurich, Zentralbibliothek, WN 1143 (CO).

Notas: Esta edición incluye la «Advertencia del editor» sobre las circunstancias de la composición de la obra al principio (págs. [3]-6) y la correspondencia entre Jovellanos y su traductor francés después del texto en las páginas 127-142.

Esta edición atribuye el parlamento final de la obra a don Simón, no a don Justo. Hay una estampa en la contraportada, omitida en la versión digitalizada online.

16.

Portada: 14 | COMEDIA NUEVA I EN PROSA. I EL DELINQÜENTE I HONRADO. | PUBLÍ́CALA | DON TORIBIO SUAREZ | DE LANGREO. I FIELMENTE CORREGIDA, ADICIONADA I Y ENMENDADA EN ESTA IMPRESION. I [Dos adornos: Dos óvalos como medallas con caras que se miran] I CON LICENCIA: | VALENCIA: EN LA OFICINA DE ILDEFONSO MOMPIÉ. | 1815. | [Barra] I Se hallará en la librería de Miguel Domingo, calle de Caballeros I núm. 48; asimismo otras de diferentes títulos, y un surtido de 185 I Saynetes por mayor y á la menuda. I

Formato y colación: $4^{\circ}[\mathrm{A}]$ B-D ${ }^{4}$.

Paginación: 1-2 [3]-20 [21] 22-32.

Fuente de la descripción: El ejemplar de la Biblioteca General Histórica de la Universidad de Salamanca, BG/52541 (8).

Versión digitalizada: No consta.

Registro en el CCPBE: No consta.

Registro en la Bibliografía de Aguilar Piñal: IV, 5169.

Íncipit: Torq. No hay remedio: ya es preciso tomar algun partido.

Éxplicit: Just. [...] Vamos á tratar de vuestro destino, y demos gracias á la inefable Providencia, que nunca abandona á los virtuosos, ni se olvida de los inocentes oprimidos.

Versión del texto empleada: B.

Ejemplares localizados:

New Haven, Yale University Library, He77 2614 (CO).

Salamanca, Universitaria, BG/52541 (8) (E).

17.

Portada: $N$. 46.I EL DELINCUENTE HONRADO. I COMEDIA EN CINCO ACTOS, EN PROSA. I PUBLÍCALA I DON TORIBIO SUAREZ DE LANGREO. I FIELMENTE CORREGIDA, ADICIONADA I Y ENMENDADA EN ESTA IMPRESION. I Colofón: VALENCIA, I IMPRENTA DE ILDEFONSO MOMPIÉ. | 1818. | 
Formato y colación: $4^{\circ}$. 1-4 4 .

Paginación: [1] 2-29 [30-32].

Fuente de la descripción: El ejemplar de la Real Academia Española, 41-1-17 (14).

Versiones digitalizadas: Google Libros reproduce el ejemplar de la Biblioteca de Catalunya, Tus-8-8720. También hay un ejemplar digitalizado de la Biblioteca de Asturias «Ramón Pérez de Ayala» de Oviedo, Ast R C 39-10 BVA.

Registro en el CCPBE: CCPB000694567-8.

Registro en la Bibliografía de Aguilar Piñal: IV, 5170.

Íncipit: Torc. No hay remedio: ya es preciso tomar algun partido.

Éxplicit: Just. [...] Vamos á tratar de vuestro destino, y demos gracias á la inefable Providencia, que nunca abandona á los virtuosos, ni se olvida de los inocentes oprimidos.

Versión del texto empleada: B.

Ejemplares localizados:

Baltimore, Johns Hopkins University Library, PJ1233 .A2 C6 t.2 c. 1 (CO).

Barcelona, Biblioteca de Catalunya, Tus-8-8720 (E).

Barcelona, Institut del Teatre, 45258 (E).

Berlín, Staatsbibliothek, 7 in:4” Xk 1202 (CO); 2 in:4” Xk 1500.10 (CO).

Chicago, University Library, PQ6217.C73 v.5 (CO).

Durham (NC), Duke University Library, Bd. Pam. 862.08 C732 c.1 (CO).

Madrid, Biblioteca Nacional, T-38711 (E).

Madrid, Real Academia Española, 41-1-17 (14) (E).

Oviedo, Biblioteca de Asturias «Ramón Pérez de Ayala», Ast R C 39-10 (BVA) (CO).

Notas: El texto ocupa las páginas [1]-29. Las tres páginas finales [30-32] contienen un «Catálogo de las comedias existentes en la Casa de los Señores Domingo y Mompié, del Comercio de Libros de Valencia,...».

El catálogo online de la Staatsbibliothek de Berlín no menciona el nombre del impresor de sus dos ejemplares, pero deben de corresponder a esta edición.

18.

Portada: NOCHES LÚGUBRES, | Por | El Coronel D. José CADALSO; I SEGUIDAS DEL I DELINQÜENTE HONRADO, I DRAMA EN PROSA, I Por D. Melchor Gaspar de JOVELLANOS. I [Anagrama del impresor] I BURDEOS, I En la Imprenta de Lawalle jóven, I paseo de Tourny, $\mathrm{N}^{\circ} .20$. I [Filete] | 1818. I

Formato y colación: $18^{\circ} .1^{12}, 2^{6}, 3^{12}, 4^{6}, 5^{12}, 6^{6}, 7^{12}, 8^{6}, 9^{12}, 10^{6}, 11^{12}, 12^{6}, 13^{12}$, $14^{6}$. 
Paginación: [2] [1-3] 4-252. El texto de El delincuente honrado ocupa las págs. 91-247.

Fuente de la descripción: El ejemplar de la Real Academia Española, 39-X-27.

Versión digitalizada: Disponible a través del ejemplar de Munich: Bayerische StaatsBibliothek digital, P.o.hisp. $28 \mathrm{~m}$.

Registro en el CCPBE: CCPB000322995-5.

Registro en la Bibliografía de Aguilar Piñal: IV, 5171.

Íncipit: ToRcuato. No hay remedio: ya es preciso tomar algun partido.

Éxplicit: Simon [sic]. [...] Vamos á tratar de vuestro destino, y demos gracias á la inefable Providencia que nunca abandona á los virtuosos, ni se olvida de los inocentes oprimidos.

Versión del texto empleada: B.

Ejemplares localizados:

Bamberg, Staatsbibliothek, 22/L.hisp.d.2 (CO).

Bolonia, Biblioteca comunale dell'Archiginnasio, 9.BB.V.23 (B).

Freiburg, Universitätsbibliothek, E 1086 (CO y CI).

Madrid, Real Academia Española, 39-X-27 (E).

Madrid, Biblioteca Nacional, 1-15499 (E).

Manchester, John Rylands Library, Special Collections R27484 (CO).

Munich, Bayerische StaatsBibliothek, P.o.hisp. 28 m (CO).

Nueva York, New York Public Library, NPC (Cadalso, J. Noches lugubres) (CO). Oviedo, Biblioteca de Asturias «Ramón Pérez de Ayala», Ast R. 2999 (CO).

París, Bibliothèque Nationale, YG 3012 (CO).

Washington, University Library, 860 P399 (CO).

Notas: Esta edición atribuye el parlamento final de la obra a don Simón, no a don Justo.

19.

Portada: N. 46. I EL DELINCUENTE HONRADO. I COMEDIA EN CINCO ACTOS, EN PROSA. I PUBLICALA I DON TORIBIO SUAREZ DE LANGREO. I FIELMENTE CORREGIDA, ADICIONADA I Y ENMENDADA EN ESTA IMPRESION. I [Adorno tipográfico] I

Colofón: VALENCIA: I IMPRENTA DE ILDEFONSO MOMPIÉ. | 1822. I [Filete] | Se hallará en su misma imprenta y librería, calle nueva de San Fernando, I números 63 y 64, junto al Mercado; y asimismo un gran surtido de CoI medias antiguas y modernas, Tragedias, Piezas en un acto, Sainetes I y Unipersonales. $\mid$

Formato y colación: $4^{\circ} .1-3^{4}, 4^{2}$.

Paginación: [1] 2-28. 
Fuente de la descripción: El ejemplar de la British Library, 1342.e.10 (1).

Versión digitalizada: No consta.

Registro en el CCPBE: CCPB000632679-X. Registra dos ejemplares, en la Biblioteca Municipal de Zaragoza y en la Biblioteca del Seminario de Barcelona.

Registro en la Bibliografía de Aguilar Piñal: IV, 5172.

Íncipit: Torc. No hay remedio: ya es preciso tomar algun partido.

Éxplicit: Just. [...] Vamos á tratar de vuestro destino, y demos gracias á la inefable Providencia que nunca abandona á los virtuosos, ni se olvida de los inocentes oprimidos.

Versión del texto empleada: B.

Ejemplares localizados:

Barcelona, Biblioteca Pública Episcopal del Seminario de Barcelona, 241.12 Zav (CO).

Berlín, Staatsbibliothek, 17 in: Xk 1441 (CO).

Londres, British Library, 1342.e.10 (1) (E).

Madrid, Biblioteca Nacional, T-10865 (E).

Santa Barbara, University of California, Santa Barbara. Davidson Library, Special Collections PQ6532.J7 D4 (CO).

Santander, Biblioteca de Menéndez Pelayo, 353 (CO).

Santiago de Compostela, Biblioteca Xeral, RSE.FOLL IV 7 (CO).

Zaragoza, Biblioteca Municipal, TR 2/22 (CO).

Notas: Hay una descripción detallada de esta edición en Germán VEGA GarcíaLuengos et al, Ediciones de teatro español en la Biblioteca de Menéndez Pelayo (hasta 1833), vol. I, págs. 381-382.

El catálogo online de la Staatsbibliothek de Berlín no menciona el nombre del impresor de su ejemplar, pero debe de corresponder a esta edición.

20.

Portada: NOCHES LÚGUBRES, I POR I El CoRonel D. José CADALSO; I Seguidas del I DELINQUENTE HONRADO, I DRAMa en PRosa, I Por D. MElChor GaSPar DE JOVELLANOS, I Segunda Edicion. I [Filete] I BURDEOS, I En Casa de LAWALLE JÓVEN Y SOBRINO, I paseo de Tourny, $\mathrm{n}^{\circ}$. 20. I [Filete] | 1823. | Formato y colación: $18^{\circ} .1^{12}, 2^{6}, 3^{12}, 4^{6}, 5^{12}, 6^{6}, 7^{12}, 8^{6}, 9^{12}, 10^{6}, 11^{12}, 12^{6}, 13^{12}$, $14^{6}$.

Paginación: [1-5] 6-249. El delinquente honrado ocupa las págs. [101]-242. Fuente de la descripción: El ejemplar de la British Library, 1480.a.27.

Versión digitalizada: La Hathi Trust Digital Library reproduce el ejemplar de Princeton, 3167.9.368. ${ }^{\circ}$ 
Registro en el CCPBE: CCPB000651536-3.

Registro en la Bibliografía de Aguilar Piñal: No consta.

Íncipit: TORQUATO. No hay remedio: ya es preciso tomar algun partido.

Éxplicit: SIMON [sic]. [...] Vamos á tratar de vuestro destino, y demos gracias á la inefable Providencia que nunca abandona á los virtuosos, ni se olvida de los inocentes oprimidos.

Versión del texto empleada: B.

Ejemplares localizados:

Boston (MA), Atheneum, VHXD .C11 (CO).

Londres, British Library, 1480.a.27 (E).

Madrid, Biblioteca Histórica Municipal, Tea 1-103-12,b (E).

Oberlin (OH), Oberlin College Library, 862.4 C113N (CO).

París, Bibliothèque Nationale, Y2-20450 (CO).

Princeton, University Library, 3167.9.368 (CO).

Notas: Esta edición atribuye el parlamento final de la obra a don Simón, no a don Justo.

La copia digital hecha por Google del ejemplar de Princeton parece carecer de portada.

21.

Portada: NOCHES LUGUBRES I POR I D. ${ }^{\mathrm{n}}$ José CADALSO. I NUEVA EDICION, I A la que se ha añadido I EL DELINCUENTE I HONRADO, I DRAMA EN CINCO ACTOS.I [Ornamento tipográfico] I BURDEOS, I IMPRENTA DE D. ${ }^{\mathrm{n}}$ PEDRO BEAUME, I ALAMEDA DE TOURNY, N. ${ }^{\circ} 5$. I 1827. I

Formato y colación: $8^{\circ}$. 1-17 ${ }^{8}$.

Paginación: [2] i-iv, [1] 2-263. El texto de la obra de Jovellanos ocupa las págs. [101]-263.

Fuente de la descripción: El ejemplar de la Biblioteca de Catalunya, Tus-87069.

Versión digitalizada: Google Libros reproduce el ejemplar de la Biblioteca de Catalunya, Tus-8-7069.

Registro en el CCPBE: CCPB000688679-5. Registra solo el ejemplar de la Biblioteca de Catalunya.

Registro en la Bibliografía de Aguilar Piñal: No consta.

Íncipit: TORCUATO. No hay remedio: ya es preciso tomar algun partido.

Éxplicit: SIMON [sic]. [...] Vamos á tratar de vuestro destino, y demos gracias á la inefable Providencia que nunca abandona á los virtuosos, ni se olvida de los inocentes oprimidos.

Versión del texto empleada: B. 
Ejemplares localizados:

Baltimore, Johns Hopkins University Library, PJ1510.C25 N6 1827 c. 1 (CO).

Barcelona, Biblioteca de Catalunya, Tus-8-7069 (E).

Notas: Esta edición atribuye el parlamento final de la obra a don Simón, no a don Justo. 


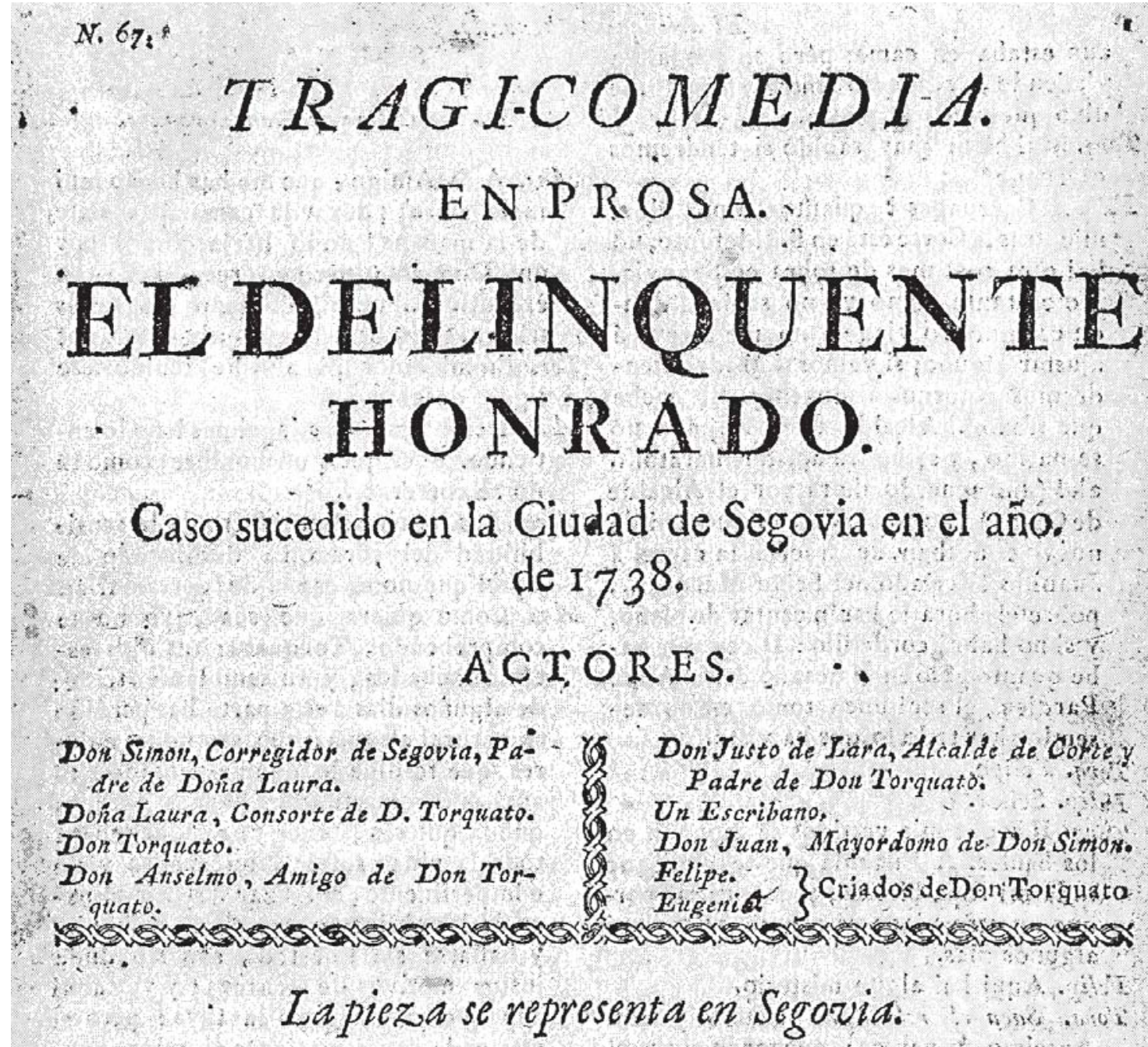

1. A C T I.

\section{SCEN A. I.}

Ruarto de estudio del Corregidor, cors uta mesa y alguinos papelis encima de clla, y Don. Forquato sentado junto b ella.

Torq. $\sqrt{O}$ hal remedio: es fuerza que yotome alguin partido las diligencias que se practican son mui vivas, y mi delito se vá á descubrir; ay Laura! adoráda Laura! ¿qué dirốs quando sepas que yo he sido el matador de tu primer esposos? no pódrás perdonárive... pero mi Amigo tarda mucho, y yo'no puedo sosegal un momento.f este $\mathrm{Mi}$ nistro que ha venido al ségúimieńto de la causa es zan activo... zy dónte halla. ré yo un asilo colitua el rigór de lás le yes ?... ah ! mi amor- y my delito me

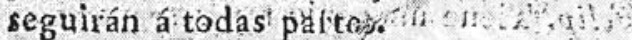

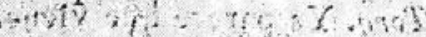
$5 \mathrm{CEN} A \mathrm{IT}$.

\section{Felipe, y DoreTorizato. ititi}

Fetip. Señor, el Señor Don Arselmo vendía al instante: mélicierom entrar á su quarto para darle el recado, porque A. aแn

Fig. 1. Portada de una edición impresa por Gibert y Tutó (Inv. 4) 
Nim. .

\section{TRAGI-COMEDIA :}

\section{EL}

\section{DELINQUENTE H O N R A D O.}

Caso sucedido en la Ciudad de Segovia en el año de $173^{8}$.

\section{A C T.OR E S:}

Don Simon, Corregidor de Segovia y Padre de Doña Lau a.

Doña Laura, consorte de D. Torquato.

Don Tarquato.

Don insermo, amigo de Don Torquato.
Don Fusto de Lara, Alcalde de Corte y Padre de Don Torquato.

Un Escribano.

Don Fuan, Mayordomo de Don Simon.

Felipe. I Criados de Don TorEugenia. $\int$ quato.

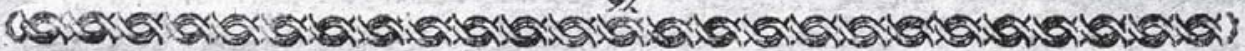

\section{La Pieza se representa en Segovia.}

\section{A C T O I.}

SCENA I.

Quarto de estudio del Corregidor, son una mesa y algunos papeles encima de ella, y Don Torquato sentado jwito á ella.

Iorq. $O$ hay remedio : es fuerza que yo tome algun partido; las diligencias que se praciican son muy vivas, y ui i delito se va á descubrir; ay Laura! adorada Laura! Qué dirás quando sepas que yo he sido al matador de tu primer esposo? No podrás perdonarme::- pero $\mathrm{mi}$ emigo tarda mucho, y yo no puedo sosegar un momento::- este Ministro que ha venido al seguimiento de la causa es $\tan$ activo:: $-y$ dónde hallasé yo ua asilo contra el rigor de las leyes?::- Ah! mi amor y mi delito me seguirán á todas partes.

\section{SCENA II.}

\section{Fellpe y Don Torquaio.}

Felip. Señor, el Señor Don Anselmo vendrá al instante : me hicieron entrar á su quarto para darle el recado, porque aun estaba en cama ; pero se queda ya vistiendo, y medio entre sueños me dixo que venia al punto.

Torq. Muy bien; has sabido si tendremos carruages?

Felip. Carruages? quantos vm. pida; mientras la Corte está en S. Ildefonso, no hay ntra cosa mas de sobra en Segovia. No obstante, como yo no sabia á donde era nuestro viage, no me atreví á ajustar alguıo; si va. mos a Madrid tendremos retornos á dozenas. El coche que traxo el Al-

A

cal-

Fig. 2. Portada de una edición impresa por Juan Francisco Piferrer (Inv. 6) 
Núm. 1.

\section{TRAGI-COMEDIA:}

\section{EL DELINCUENTE HONR A DO.}

Caso sucedido en la ciudad de Segovia en el año de $173^{8}$.

\section{A C T O R E S.}

Don Simon, Corregidor de Segoviay Pa-

dre de Doña Laura.

Doña Laura, consorte de D: Torcuato.

Don Torcuato.

Don Anselmo, amigo de Don Torcuato.
Don Justo de Lara. Alcalde de Corte $y$ Padre de Don Torcuato.

Un Escribano.

Don Juan, Mayordomo de Don Simon. $\left.\begin{array}{l}\text { Felipe. } \\ \text { Eugenia. }\end{array}\right\}$ Criados de D. Torcuato.

\section{La pieza se representa en Segovia.}

\section{ACTO I.}

\section{ESCENA I.}

Cuarto de estudio del" Corregidor, con una mesa $y$ algunos papeles encima de ella, y D. Torcuato sentado junto á ella.

Torc.

orc. Way remedio es fuerza que yo tome algun partido, las diligencias que se practican son muy vivas, y mi delito se va á descubrir; ay Laura! adorada Laura! Qué dirás cuando sepas que yo he sido el matador de tu primer esposo? No podrás perdonarme : : - pero mi amigo tarda mucho, y yo no puedo sosegar un momento: :- este Ministro que ha ve. nido al seguimiento de la causa es tan activo: : - y dónde hallaré yo un asilo contra el rigor de las leyes ?: : Ah! mi amor y mi delito me seguirán á todas partes.

\section{ESCENA II.}

\section{Felipe y Don Torcuato.}

Fel. Sefíor, el señor D. Anselmo vendrá al instante : me hicieron eutrar á su cuarto para darle el recado, porque aun estaba en cama; pero se queda ya vistiendo, y medio enrre soeños me dijo que venia al punto.

Torc. Muy bien; has sabido si tendremos carruages?

Fel. Carruages? cuantos V. pida; mientras la Corte está en S. IIdefonso, no hay otra cosa mas de sobra en Segovia. No obstante, como yo no sabía á donde era nuestro viaje; no me atreví á ajustar alguno; si vamos á Madrid tendremos retornos á docenas. El coche que trae al Alcalde de

Fig. 3. Portada de otra edición impresa por Juan Francisco Piferrer (Inv. 8) 